\title{
Differential Subcellular Recruitment of Monoacylglycerol Lipase Generates Spatial Specificity of 2-Arachidonoyl Glycerol Signaling during Axonal Pathfinding
}

\author{
Erik Keimpema, ${ }^{1 \star}$ Klaudia Barabas, ${ }^{1 *}$ Yury M. Morozov, ${ }^{3}$ Giuseppe Tortoriello, ${ }^{1}$ Masaaki Torii, ${ }^{3}$ Gary Cameron, ${ }^{2}$ \\ Yuchio Yanagawa, ${ }^{4,5}$ Masahiko Watanabe, ${ }^{6}$ Ken Mackie, ${ }^{7}$ and Tibor Harkany ${ }^{1,8}$ \\ ${ }^{1}$ European Neuroscience Institute at Aberdeen and ${ }^{2}$ Division of Applied Medicine, Aberdeen AB25 2ZD, United Kingdom, ${ }^{3}$ Department of Neurobiology, \\ Kavli Institute for Neuroscience, Yale University School of Medicine, New Haven, Connecticut 06510, ${ }^{4}$ Department of Genetic and Behavioral Neuroscience, \\ Gunma University Graduate School of Medicine, Maebashi 371-8511, Japan, ${ }^{5} J a p a n$ Science and Technology Agency, Tokyo 102-0075, Japan, ${ }^{6}$ Department \\ of Anatomy, Hokkaido University School of Medicine, Sapporo 060-8638, Japan, ${ }^{7}$ Gill Center for Neuroscience and Department of Psychological and Brain \\ Sciences, Indiana University, Bloomington, Indiana 47405, and ${ }^{8}$ Division of Molecular Neurobiology, Department of Medical Biochemistry and Biophysics, \\ Karolinska Institute, S-17177 Stockholm, Sweden
}

Endocannabinoids, particularly 2-arachidonoyl glycerol (2-AG), impact the directional turning and motility of a developing axon by activating $\mathrm{CB}_{1}$ cannabinoid receptors $\left(\mathrm{CB}_{1} \mathrm{Rs}\right)$ in its growth cone. Recent findings posit that $s n$-1-diacylglycerol lipases $(\mathrm{DAGL} \alpha / \beta)$ synthesize 2-AG in the motile axon segment of developing pyramidal cells. Coincident axonal targeting of $\mathrm{CB}_{1}$ Rs and DAGLs prompts the hypothesis that autocrine 2-AG signaling facilitates axonal outgrowth. However, DAGLs alone are insufficient to account for the spatial specificity and dynamics of 2-AG signaling. Therefore, we hypothesized that local 2-AG degradation by monoacylglycerol lipase (MGL) must play a role. We determined how subcellular recruitment of MGL is temporally and spatially restricted to establish the signaling competence of 2-AG during axonal growth. MGL is expressed in central and peripheral axons of the fetal nervous system by embryonic day 12.5. MGL coexists with DAGL $\alpha$ and $\mathrm{CB}_{1}$ Rs in corticofugal axons of pyramidal cells. Here, MGL and DAGL $\alpha$ undergo differential axonal targeting with MGL being excluded from the motile neurite tip. Thus, spatially confined MGL activity generates a 2-AG-sensing microdomain and configures 2-AG signaling to promote axonal growth. Once synaptogenesis commences, MGL disperses in stationary growth cones. The axonal polarity of MGL is maintained by differential proteasomal degradation because inhibiting the ubiquitin proteasome system also induces axonal MGL redistribution. Because MGL inactivation drives a $\mathrm{CB}_{1} \mathrm{R}$-dependent axonal growth response, we conclude that 2-AG may act as a focal protrusive signal for developing neurons and whose regulated metabolism is critical for attaining correct axonal complexity.

\section{Introduction}

Acquisition of a characteristic neuronal cytoarchitecture and connectivity pattern relies on signaling cassettes whose coordinated expression and temporal interplay drive neuronal identification in the developing nervous system (Ibáñez and Ernfors,

Received April 26, 2010; revised Aug. 6, 2010; accepted Aug. 13, 2010.

This work was supported by the Scottish Universities Life Science Alliance (T.H.), European Molecular Biology Organization Young Investigator Programme (T.H.), Swedish Medical Research Council (T.H.), Alzheimer's Research Trust UK (T.H.), Alzheimer's Association (K.M., T.H.), European Commission Grant HEALTH-F2-2007-201159 (T.H.), Grant-in-Aid for Scientific Research from the Ministry of Education, Culture, Sports, Science, and Technology of Japan (Y.Y.), Takeda Science Foundation (Y.Y.), the March of Dimes Birth Defects Foundation (Y.M.M.), the Kavli Institute for Neuroscience at Yale University (Y.M.M.), and National Institutes of Health Grants DA023214 (T.H.), DA11322 (K.M.), and DA21696 (K.M.). We thank C. Ledent and Y. A. Barde for colony founders of $C B_{7} R^{-/-}$and tau-EGFP mice, respectively. Y.Zilberter, H.-C. Lu, R. lyengar, R. A. Ross, and P. Doherty are acknowledged for their constructive criticism. We thank R. Hessling and J. Lindenau (Carl Zeiss) for expert advice and assistance with quantitative immunofluorescence analysis.

${ }^{*}$ E.K. and K.B. contributed equally to this work.

Correspondence should be addressed to Dr. Tibor Harkany, European Neuroscience Institute at Aberdeen, University of Aberdeen, Foresterhill Campus, Ashgrove Road West, Aberdeen AB25 2ZD, United Kingdom. E-mail: t.harkany@abdn.ac.uk.

DOI:10.1523/JNEUROSCI.2126-10.2010

Copyright $\odot 2010$ the authors $\quad 0270-6474 / 10 / 3013992-16 \$ 15.00 / 0$
2007; Fishell and Hanashima, 2008). Endocannabinoid (eCB) signaling affects neural state change decisions either directly (Berghuis et al., 2007) or by interacting with neurotrophin (Maison et al., 2009) or cytokine signaling (Zorina et al., 2010). The discovery that neuronal lineage commitment and axonal polarization coincide with $\mathrm{CB}_{1}$ cannabinoid receptor $\left(\mathrm{CB}_{1} \mathrm{R}\right)$ expression (Coutts et al., 2001; Begbie et al., 2004; Berghuis et al., 2007; Mulder et al., 2008) and persist in the presence of a particularly high 2-arachidonoyl glycerol (2-AG) tone (Berrendero et al., 1999) prompted the view that downstream signaling from $\mathrm{CB}_{1}$ Rs diversifies the cellular outcome of eCB signaling in developing neurons (Bromberg et al., 2008). In contrast, the developmental dynamics of 2-AG signaling entailing coordinated expression of the 2-AG synthesizing and degrading enzymes $s n$-1-diacylglycerol lipases $\alpha / \beta$ (DAGL $\alpha / \beta$ ) (Bisogno et al., 2003) and monoacylglycerol lipase (MGL) (Dinh et al., 2002), respectively, remain essentially unexplored. Understanding spatial and temporal constraints of the metabolic network responsible for regulating 2-AG bioavailability is necessary to appreciate the physiological significance of 2-AG in the hierarchy of integrative signaling networks that determine neuronal identity. 
The process of directional axonal growth relies on multimodal communication between individual axons while they navigate through brain microdomains presenting a spectrum of attractive and repulsive guidance cues (Xiang et al., 2002). eCB signaling is a novel mechanism positioned to facilitate corticofugal axon (CFA) development (Watson et al., 2008) because axonal targeting of DAGL $\alpha / \beta$ can generate cell-autonomous 2-AG microgradients engaging $\mathrm{CB}_{1}$ Rs in motile growth cones (Bisogno et al., 2003). Alternatively, 2-AG released from corticofugal axons can act as a paracrine guidance signal and limit premature dispersion of axon collaterals by establishing permissive pathfinding corridors (Mulder et al., 2008). Accordingly, impaired $\mathrm{CB}_{1} \mathrm{R}$ function during growth cone navigation presents an aberrant axon fasciculation and postsynaptic target selection phenotype (Berghuis et al., 2007; Watson et al., 2008). However, the above model is incomplete because it neither identifies an axonal domain whose cytoskeletal dynamics are particularly sensitive to eCBs nor explains how eCB actions are restricted to the distal motile axon segment to drive its unidirectional extension. Therefore, an adequate mechanistic concept must imply focal 2-AG-degrading activity, likely produced by MGL, known to degrade $85-90 \%$ of 2-AG in adult brain homogenates (Blankman et al., 2007), to restrict 2-AG signaling to the navigating growth cone and away from the consolidating neurite shaft.

Here, we explored the developmental dynamics of MGL expression and its spatial relationship with $\mathrm{CB}_{1} \mathrm{R}$ and DAGL $\alpha / \beta$ during forebrain development. We identify a metabolic regulatory network allowing both autocrine and paracrine 2-AG signaling to operate in developing brain with $\mathrm{CB}_{1} \mathrm{R}$ being dispensable to regulate the expression and correct axonal targeting of both MGL and DAGL $\alpha$. We directly implicate 2-AG signaling in axon development by demonstrating that site-directed MGL inactivation triggers a $\mathrm{CB}_{1} \mathrm{R}$-dependent axonal growth response.

\section{Materials and Methods}

Animals and tissue preparation. Mouse embryos ( $n \geq 6$ per time point, $n \geq 2$ pregnancies per analysis) were obtained from time-mated C57BL/ $6 / \mathrm{N}$, GAD67-green fluorescent protein-positive $\left(\mathrm{GFP}^{+}\right)(\Delta$ neo $)$ (Tamamaki et al., 2003), tau-enhanced GFP (EGFP) (Tucker et al., 2001), or $C B_{1} R^{-\prime-}$ and corresponding CD1 wild-type mice (Ledent et al., 1999) at embryonic day 12.5 (E12.5) to E18.5. Whole brains were immersion fixed in $4 \%$ paraformaldehyde in Na-phosphate buffer $(0.1 \mathrm{M}, \mathrm{pH}$ 7.4) overnight. Tissue samples were cryoprotected in $30 \%$ sucrose in physiological saline for at least $48 \mathrm{~h}$ before cryostat sectioning $(16 \mu \mathrm{m}$ thickness) and thaw mounting on SuperFrost ${ }^{+}$glass slides. Experiments conformed to the 86/609/EEC directive and were approved by the Home Office of the United Kingdom.

Histochemical expression profiling and quantitative microscopy. Basic concepts of forebrain development are discussed in the supplemental information (available at www.jneurosci.org as supplemental material). Serial sections were processed according to published protocols (Berghuis et al., 2007) with select combinations of primary antibodies (supplemental Table $1 A, A_{1}$, available at www.jneurosci.org as supplemental material). Hoechst 35,528 (Sigma), a nuclear dye, has been applied to reveal tissue architecture. Antibodies raised against $\mathrm{CB}_{1} \mathrm{R}$, its C-terminal interacting protein 1a isoform (CRIP1a), DAGL $\alpha$, and MGL (Twitchell et al., 1997; Yoshida et al., 2006; Uchigashima et al., 2007; Straiker et al., 2009) were independently validated by at least two of the following methods: (1) preadsorption of primary antibodies with their corresponding fusion protein $(5 \mu \mathrm{g} / \mathrm{ml})$ in vitro and/or in vivo, (2) colocalization with hemagglutinin-tagged target protein heterologously expressed in human embryonic kidney HEK293 cells, (3) lack of staining in corresponding null mice (data not shown for DAGL $\alpha$ or MGL), or (4) identical staining patterns by multiple antibodies recognizing distinct epitopes within a target protein (supplemental Figs. 1-3, available at www.jneurosci.org as supplemental material).
Sections were inspected, and images were acquired on a 710LSM confocal laser-scanning microscope (Carl Zeiss) equipped to separate emission signals through spectral detection and unmixing. Emission spectra for each dye was limited as follows: Hoechst (420-485 nm), carbocyanine 2 (Сy2) (505-530 nm), Сy3 (560-610 nm), and Cy5 (640-720 nm). Image surveys were generated using the tile scan function with optical zoom ranging from $0.6 \times$ to $1.5 \times$ at $10 \times$ primary magnification (objective, EC Plan-Neofluar $10 \times / 0.30$ ). Images were processed using the ZEN2009 software (Carl Zeiss). Multipanel figures were assembled in CorelDraw X3 (Corel Corp.).

Colocalization was defined as immunosignals being present without physical signal separation in $\leq 1.0 \mu \mathrm{m}$ optical slices at $40 \times$ (PlanNeofluar $40 \times / 1.30)$ or $63 \times($ Plan-Apochromat $63 \times / 1.40)$ primary magnification (Mulder et al., 2009). The colocalization utility of the ZEN2009 software package was used to determine (1) the relative area occupancy for each fluorochrome, defined as the density of fluorescence pixels normalized to a $1 \mu \mathrm{m}^{2}$ surface area, (2) the colocalization coefficient of $\mathrm{CB}_{1} \mathrm{R}$ versus MGL immunoreactivities in the cortical plate or thalamus, expressed as the relative number of colocalizing pixels in one channel compared with the total number of pixels above threshold in another channel, and (3) Pearson's correlation coefficient defining the intensity distribution within colocalizing regions (ranging from -1 to +1 , with 0 indicating no correlation).

Preembedding electron microscopy. E13-E13.5 mouse embryos were decapitated, and brains were immersion fixed overnight (Morozov et al., 2009). Preembedding immunoperoxidase labeling to localize $\mathrm{CB}_{1} \mathrm{Rs}$ in coronal vibratome sections $(100 \mu \mathrm{m})$ was performed with specimens subsequently osmificated and contrasted (Morozov et al., 2009).

In utero electroporation. At E11.5, in utero electroporation was performed as described previously (Torii et al., 2009) by injecting a DNA solution containing a pCAGGS-EGFP plasmid at a concentration of 0.5 $\mathrm{mg} / \mathrm{ml}$ using a pulled glass capillary. Electroporation was performed using a BTX ECM830 square wave electroporator with five electric pulses at $25 \mathrm{~V}$ for $50 \mathrm{~ms}$ each with $950 \mathrm{~ms}$ intervals (Morozov et al., 2009). Dams were decapitated after 3-6 d, and embryos were removed and inspected for EGFP fluorescence (Stemi SV11 Apo; Carl Zeiss). EGFP-expressing brains were immersion fixed and sectioned, and $\mathrm{CB}_{1}$ Rs were localized as above.

Neuronal cultures, immunocytochemistry, and morphometry. Embryonic cortices and hippocampi were dissected at E14.5 or E16.5. Cells were dissociated by trypsin $(0.1 \%)$ and plated on coverslips coated with polyD-lysine (PDL) (Sigma). Cultured neurons (30-50,000 cells per well in 24 -well plates) were maintained for 2 or $4 \mathrm{~d}$ in vitro (DIV) as described previously (Mulder et al., 2008). Lactacystin (20 $\mu \mathrm{M}$; Tocris Bioscience), an irreversible inhibitor of the $20 \mathrm{~S}$ proteasome, the DAGL inhibitors tetrahydrolipstatin (THL) ( $1 \mu \mathrm{M}$; Sigma) and O-3841 ( $1 \mu \mathrm{M})$ (Bisogno et al., 2006), the MGL inhibitors JZL184 (100 nM; Cayman Chemical) (Long et al., 2009) and URB 602 (5 $\mu \mathrm{M}$; Cayman Chemical) (King et al., 2007), and the neutral $\mathrm{CB}_{1} \mathrm{R}$ antagonist O-2050 (200 nm; Tocris Bioscience) were added to modulate axonal MGL distribution and growth rates as well as to induce growth cone collapse. Immunocytochemistry was performed with select combinations of primary antibodies (supplemental Table 1, available at www.jneurosci.org as supplemental material) (Berghuis et al., 2007). The Dotti staging method was used to define axon development (Dotti et al., 1988). Images of cortical neurons and their axons were captured by means of laser-scanning microscopy (model 710LSM; Carl Zeiss). Neurite length and the surface area of individual growth cones were determined at the time points indicated (see Fig. 9) by analyzing calibrated images in the LSM5 image browser software module (version 3.2.0.115; Carl Zeiss).

PCR. E16.5 embryonic brains $(n=4)$ were microdissected on ice to isolate cortical and thalamic regions and snap frozen in liquid $\mathrm{N}_{2}$ until processing. Primary cultures from cortex and thalamus were established at E16.5 and maintained for 4 DIV at a density of $1 \times 10^{6}$ cells per well in PDL-coated six-well plates ( $n=2$ per region). RNA was extracted using the RNeasy mini kit (Qiagen) with a DNase I step performed to eliminate traces of genomic DNA (supplemental Fig. $4 A_{1}, A_{2}$, available at www. jneurosci.org as supplemental material) and reverse transcribed using a high-capacity cDNA reverse transcription kit (Applied Biosystems). 
Quantitative PCRs were performed after an initial $10 \mathrm{~min} 95^{\circ} \mathrm{C}$ denaturation followed by 40 cycles of $95^{\circ} \mathrm{C}$ for $15 \mathrm{~s}$ denaturation, annealing and extension at calculated temperatures $(60 \mathrm{~s})$, and a dissociation stage (from 60 to $95^{\circ} \mathrm{C}$ with $0.5^{\circ} \mathrm{C}$ steps for $10 \mathrm{~s} \mathrm{each}$ ) (MyiQ; Bio-Rad), with primer pairs amplifying short fragments for each gene (supplemental Fig. $4 B$, available at www.jneurosci.org as supplemental material). Samples without template or reverse transcriptase served as negative control. Expression levels were obtained by subtracting the value for each sample in the absence of reverse transcriptase from the corresponding value in the presence of reverse transcriptase and then normalizing to the housekeeping gene encoding glyceraldehyde-3-phosphate dehydrogenase (GAPDH) obtained for every sample in parallel assays (Berghuis et al., 2005).

Western blotting. Tissue samples were lysed in modified radioimmunoprecipitation assay buffer containing $1 \mathrm{~mm} \mathrm{NaF}, 1 \mathrm{mM} \mathrm{Na}_{3} \mathrm{VO}_{4}, 0.1 \%$ $N$-octyl- $\beta$-D-glucopyranoside, and a mixture of protease inhibitors (Roche), denatured in $5 \times$ Laemmli's buffer, and analyzed by SDS-PAGE (30 $\mu \mathrm{g}$ of protein per sample) (Berghuis et al., 2005). Membranes were blocked in Odyssey blocking buffer (LiCor Biosciences) for $1 \mathrm{~h}$ and exposed to primary antibodies (supplemental Table 1, available at www. jneurosci.org as supplemental material) overnight at $4^{\circ} \mathrm{C}$. $\beta$-III-Tubulin (1:2000; Promega) or $\beta$-actin (1:10,000; Promega) served as loading control. Appropriate combinations of IRDye 800 and IRDye680 antibodies (from goat or rabbit hosts; 1:10,000, $2 \mathrm{~h}$; LiCor Biosciences) were used for signal detection on a LiCor Odyssey IR imager. Integrated optical densities were determined using NIH ImageJ 1.32j. Experiments were performed in triplicate.

Liquid chromatography tandem mass spectrometry. 2-AG concentrations were determined using a solid-phase extraction liquid chromatography tandem mass spectrometry (LC-MS/MS) method (Giuffrida et al., 2000). Tissues from $n=4-8$ embryos per developmental stage were homogenized in ice-cold acetonitrile containing $\left[{ }^{2} \mathrm{H}_{4}\right]$ anandamide (AEA) at $6 \mathrm{pmol}$ as the internal standard, made up to $70 \%$ water and centrifuged at 13,000 rpm for $5 \mathrm{~min}$. The supernatant was applied to Strata-X polymeric reversed-phase cartridges (Phenomenex), methanoleluted analytes were dried under $\mathrm{N}_{2}$, and the residue was resuspended in mobile phase. A Surveyor LC system coupled to a TSQ Quantum mass spectrometer (Fisher Thermo Scientific) was used for analysis. The analytes were eluted from an ACE $5 \mu$ C 8 column $(150 \times 2.1 \mathrm{~mm}$; Hichrom Ltd.) under isocratic conditions with a mobile phase consisting of $15 \%$ water, $85 \%$ methanol, and $0.5 \%$ formic acid at a flow rate of $200 \mu \mathrm{l} / \mathrm{min}$ at $30^{\circ} \mathrm{C}$. MS analysis was performed using electrospray ionization in positive ion mode. Quantification was undertaken using single-reaction monitoring of the parent ion-product ion transitions for 2-AG and $\left[{ }^{2} \mathrm{H}_{4}\right]$ AEA of mass-to-charge ratio $(\mathrm{m} / \mathrm{z})$ of $\mathrm{m} / \mathrm{z} 379$ to $\mathrm{m} / \mathrm{z} 287$ and $\mathrm{m} / \mathrm{z}$ 352.2 to $\mathrm{m} / z$ 66.2, respectively. Two peaks were present in the chromatogram for 2-AG because a 1(3)-isomer exists in equilibrium with 2-AG. The areas of both peaks were combined to calculate [2-AG] by weighted linear regression analysis against suitable calibration standards using Xcalibur 2.0.6 software (Fisher Thermo Scientific). Results were expressed as nanomoles per gram of tissue.

Statistics. A $p$ value of $<0.05$ was considered statistically significant (Student's $t$ test) (SPSS version 16.0). Data were expressed as means \pm SEM. Fluorescence intensity distributions in individual axons were calculated by NIH ImageJ $1.32 \mathrm{j}$ and plotted in GraFit 5.0 (Erithacus Software).

\section{Results}

\section{Developmental dynamics of MGL expression}

$\mathrm{CB}_{1} \mathrm{R}$ and DAGL expression and function are tightly regulated to modulate neuronal polarization and axonal growth in the developing nervous system (Bisogno et al., 2003; Leterrier et al., 2006; Berghuis et al., 2007; Vitalis et al., 2008; Maison et al., 2009; Walker et al., 2010). Both pyramidal cells and interneurons rely on $\mathrm{CB}_{1}$ Rs to transduce eCB signals (Berghuis et al., 2007; Mulder et al., 2008). DAGL expression and cell-autonomous activity are retained only by pyramidal cells, whereas GABAergic interneurons depend on extracellular 2-AG cues (Walker et al., 2010). In contrast, the spatiotemporal dynamics of MGL expression and function in the developing nervous system remain unknown.

We generated polyclonal antibodies raised against distinct MGL epitopes (supplemental Table 1, supplemental Fig. 3, available at www.jneurosci.org as supplemental material) to determine the distribution pattern of MGL in the developing nervous system of the mouse. We find $\mathrm{MGL}^{+}$progenitors residing in the ventricular (VZ) and subventricular (SVZ) zones of the telencephalic vesicles at E12.5 (Fig. $1 A-A_{2}$ ). $\mathrm{MGL}^{+}$pioneer axons are committed to the olfactory nerve (Fig. $1 A_{1}$ ) and thalamic projections (Fig. $1 A_{2}$ ) at this developmental stage. However, GFP ${ }^{+}$ GABAergic neurons migrating toward the cerebral cortex lack appreciable MGL expression (Fig. $1 A_{1}, A_{2}$ ).

We used homozygous tau-EGFP mice to resolve the subcellular distribution of MGL in the developing mouse brain (Fig. $\left.1 B, B_{1}\right)$ as well as peripheral ganglia and nerves at E14.5. tauEGFP mice were constructed by placing EGFP cDNA in-frame with the endogenous initiation codon of the tau gene such that a fusion protein is produced comprising the first 31 aa of tau followed by EGFP (Tucker et al., 2001). The chimeric protein is particularly advantageous in a developmental context because EGFP replaces the C-terminal microtubule-binding domains of tau, resulting in an entirely cytoplasmic EGFP signal in projection neurons, such as Brn-1 ${ }^{+}$cortical pyramidal cells (Fig. $1 D_{3}$ ) (Sugitani et al., 2002) but not in $\mathrm{GABA}^{+}$interneurons (data not shown).

Peripheral ganglia, including trigeminal (Fig. 1C) and dorsal root ganglia (data not shown), harbored many $\mathrm{MGL}^{+}$neurons. Consequently, $\mathrm{MGL}^{+}$axons concentrated in facial and mandibular trunks of the trigeminal nerve, including those innervating the whiskers, the spinal trigeminal tract (Fig. $1 C_{1}, C_{2}$ ), and the stalk of the optic nerve (Fig. $1 C_{1}$ ). $\mathrm{MGL}^{+}$central structures include the parabrachial/microcellular tegmental nucleus and the colliculi superior and inferior (Fig. $1 C_{1}, C_{3}$ ). In the forebrain, the olfactory nerve, VZ/SVZ progenitors, postmitotic cortical neurons, and axons coursing along the palliosubpallial boundary, presumed thalamocortical axons (TCAs), were $\mathrm{MGL}^{+}$(Fig. $\left.1 C, C_{1}\right)$. By analyzing coronal sections of the fetal mouse brain, we confirmed that both optic nerves and TCAs traversing the inferior thalamic radiation (Fig. $1 D, D_{1}$ ) are $\mathrm{MGL}^{+} . \mathrm{MGL}^{+}$TCAs advance in the subplate as far as the medial pallial fold (Fig. 1 $\left.D_{2}\right)$ and coexist with radially migrating $\mathrm{MGL}^{+}$postmitotic neurons exiting the SVZ (but not $\mathrm{RC}^{+}{ }^{+}$radial glia) and MGL-negative $\left(\mathrm{MGL}^{-}\right) / \mathrm{GFP}^{+}$GABA cells migrating tangentially in the marginal zone of this cortical domain. In the lateroventral isocortex, $\mathrm{MGL}^{+}$ascending TCAs appear intermingled with radially migrating Brn- ${ }^{+} / \mathrm{MGL}^{+}$cortical pyramidal cells and can target these cells once they reached the cortical plate (Fig. $\left.1 D_{4}\right)$.

Most long-range forebrain tracts (Fig. $1 E$ ), including the peripheral (Fig. $1 E_{1}$ ) and central segments (Fig. $1 E_{2}$ ) of the optic nerve, lateral olfactory tract, fimbria hippocampi, and TCAs, recruit $\mathrm{MGL}^{+}$axons by E16.5, which we recognize as the developmental stage after which axonal MGL targeting terminates. After this time, MGL is restricted to the perisomatic segment and proximal dendrites both in the late-gestational brain (Fig. $1 F$ ) and at birth (data not shown). We find that restricted MGL expression inversely correlates with cortical and hippocampal 2-AG concentrations (Fig. 1G): $10.2 \pm 1.1$ (E14.5), $13.9 \pm 3.2$ (E16.5), $13.21 \pm$ $1.8(\mathrm{E} 18.5) \mathrm{ng} / \mathrm{mg}$ tissue versus $21.2 \pm 4.2$ postnatal day $0(\mathrm{P} 0)$, $35.78 \pm 7.8$ ( $\mathrm{P} 1 ; p<0.05$ vs all fetal groups examined), $44.4 \pm 9.8$ $\mathrm{ng} / \mathrm{mg}$ tissue (P2; $p<0.05$ vs all fetal groups examined). Collectively, our data suggest that MGL plays an essential role in determining 2-AG availability in the developing nervous system. 


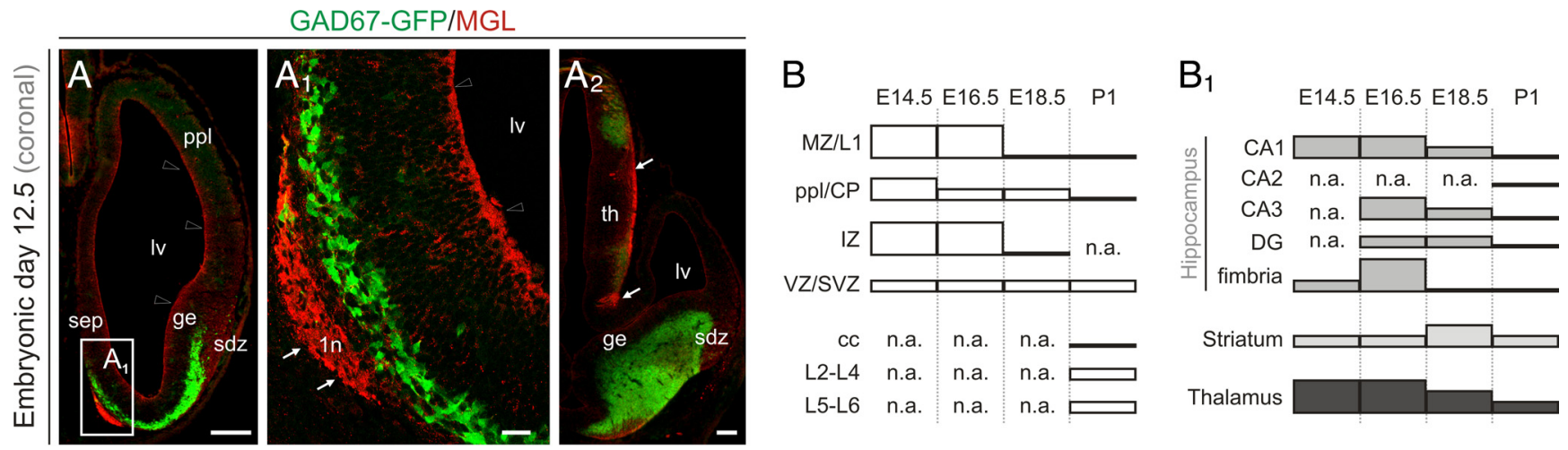

tau-EGFP/MGL/Brn-1

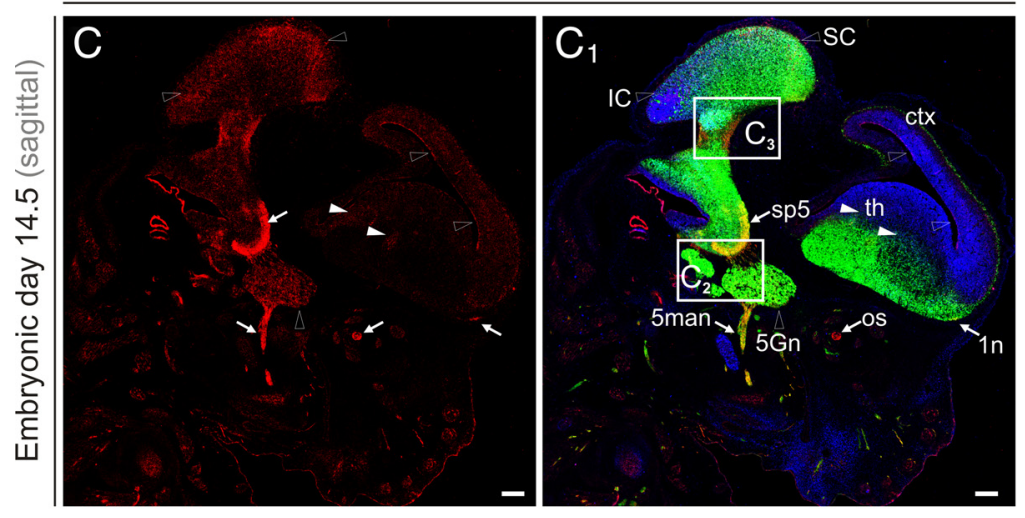

tau-EGFP/MGL/Brn-1

GAD67-GFP/MGL

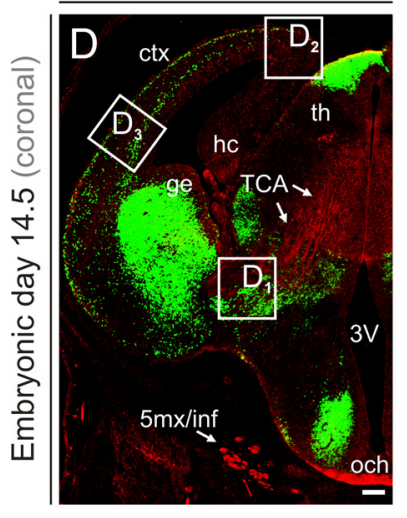

thalamus

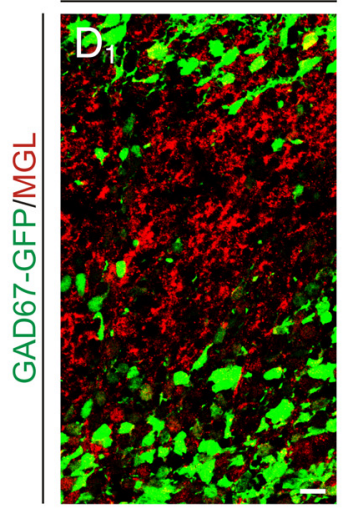

cortex

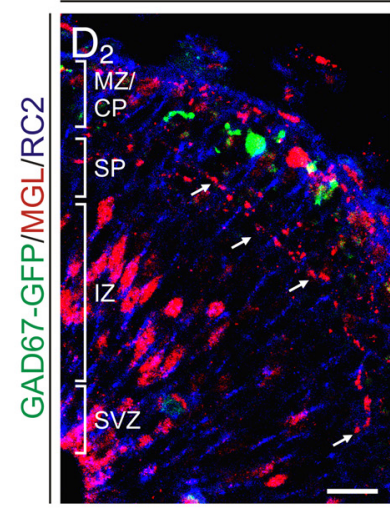

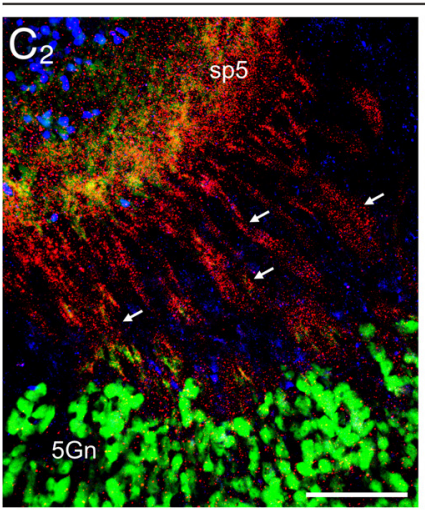

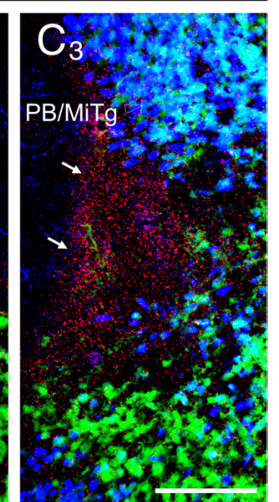

cortex

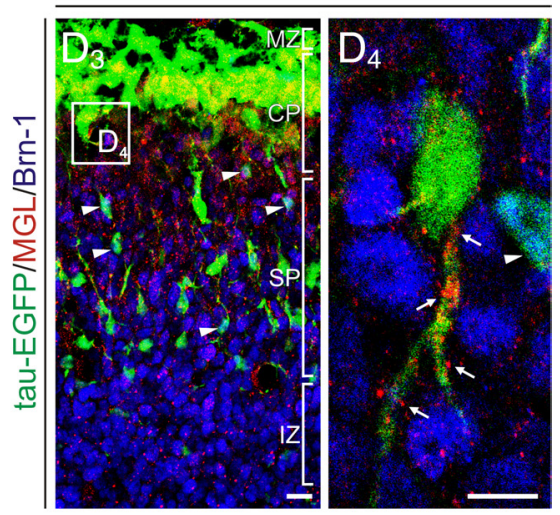

MGL/ß-III-tubulin

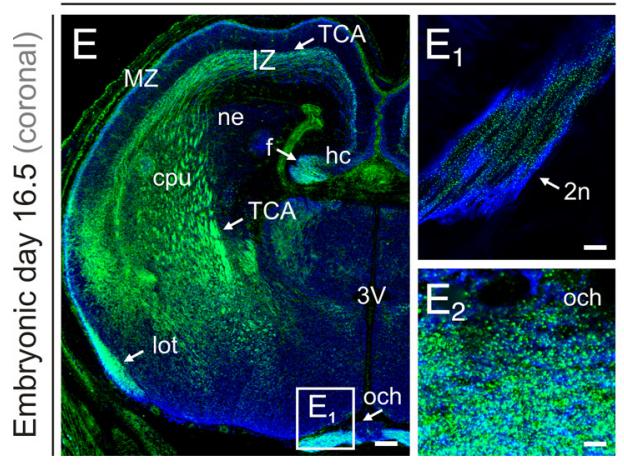

Embryonic day 18.5 (coronal)

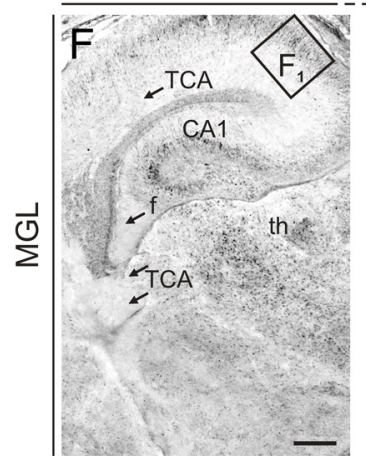

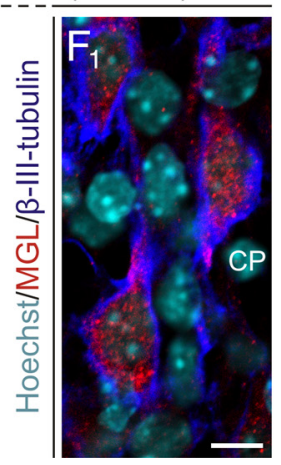

\section{G}

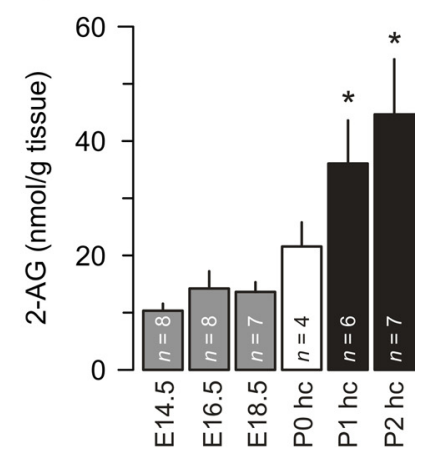

Figure 1. MGL localization in the developing nervous system. $A-A_{2}, M G L+{ }^{+}$olfactory $\left(A_{1}\right.$, arrows) and thalamic axons $\left(A_{2}\right.$, arrows), ventricular zone progenitors (open arrowheads), and precursor cells populating the striatal differentiation zone (sdz) are present by E12.5. $\boldsymbol{B}, \boldsymbol{B}_{1}$, Semiquantitative assessment of MGL distribution in postmitotic neurons of cerebral subfields. Incrementing horizontal line width correlates with increasing signal intensity. $C_{-} C_{3}$, Sagittal section across the brain and upper body segment of a homozygous tau-EGFP ${ }^{+}$embryo (Figure legend continues.) 

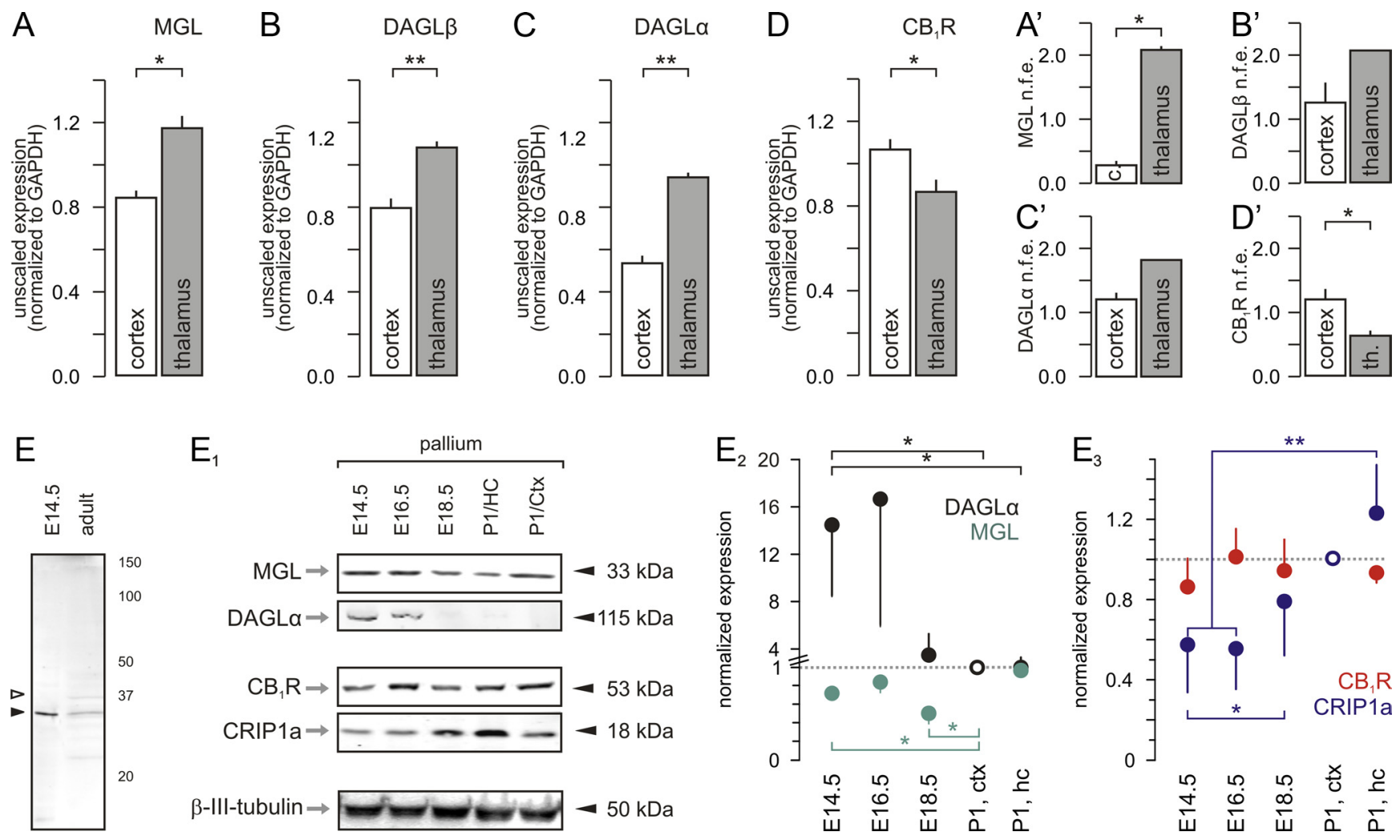

$\mathrm{E}_{1}$
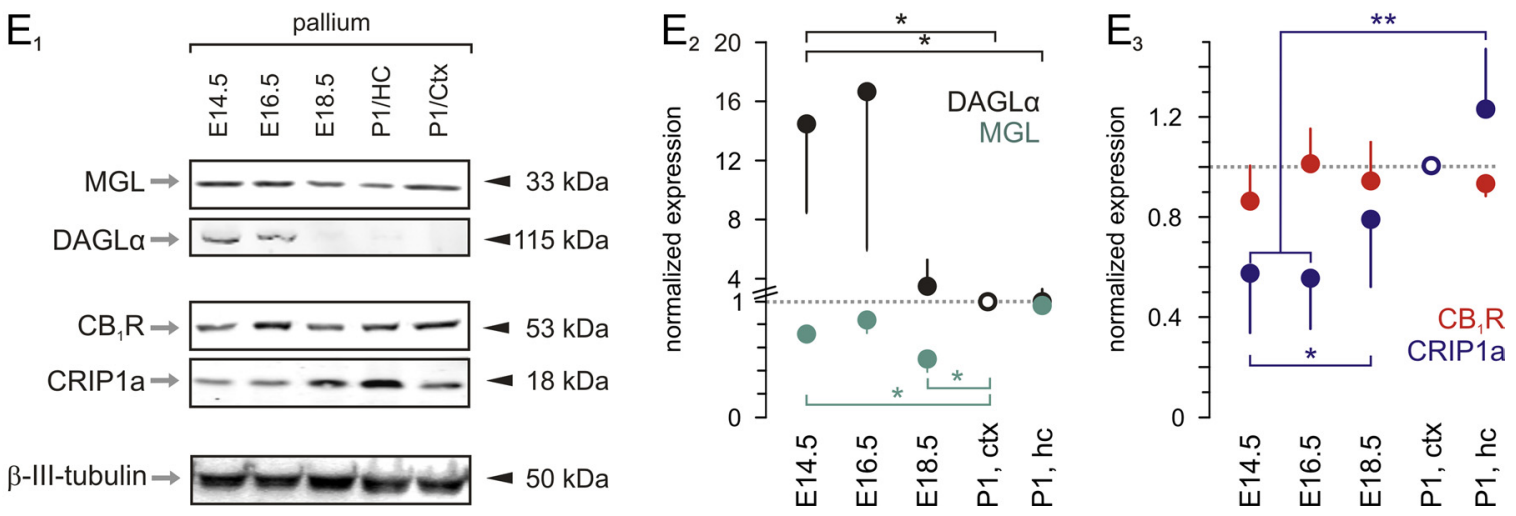

Figure 2. Foci of MGL expression and the developmental dynamics of 2-AG signaling. $A-D$, Comparative analysis of the expression levels of 2-AG metabolic enzymes and $C_{1} B_{1}$ in fetal mouse brain at E16.5. Data were normalized to GAPDH, a housekeeping gene. ${ }^{*} p<0.05$, ${ }^{* *} p<0.01$, cortex versus thalamus. $\boldsymbol{A}^{\prime}-\boldsymbol{D}^{\prime}$, Cortical and thalamic neurons maintain region-specific differences in their expression of MGL, $\mathrm{CB}_{1} \mathrm{R}$, and DAGL $\alpha / \beta$ after 4 DIV (n.f.e., normalized fold expression). $\boldsymbol{E}$, The $33 \mathrm{kDa}$ isoform of MGL predominates in fetal brain. $\boldsymbol{E}_{1}$, Western blot analysis of metabolic components of 2-AG signaling networks during successive stages of corticogenesis. $\beta$-III-Tubulin served as protein loading control. Discordant $\mathrm{CB}_{1} R$ and $\mathrm{CRIP}_{1}$ a expression patterns suggest a lack of interaction or temporally restricted CRIP1a recruitment to $C B_{1} R s . E_{2}, E_{3}$, Quantitative analysis of fetal DAGL $\alpha$, MGL, and $C B_{1} R$, CRIP1a protein levels. Data points represent mean $\pm S E M$; integrated optical density values from $n=3$ independent experiments. Neonatal cortices were used to normalize expression levels $\left({ }^{*} p<0.05,{ }^{* *} p<0.01\right.$, Student's $t$ test).

\section{Regional differences in 2-AG synthesis and degradation in the corticothalamic axis}

Previous studies support the notion that $\mathrm{CB}_{1} \mathrm{Rs}$ are primarily expressed in the developing neocortex (Berghuis et al., 2007; Vitalis et al., 2008; Morozov et al., 2009). Our present histochemical findings, however, place the primary site of MGL synthesis in the developing thalamus. We performed quantitative real-time PCR (qPCR) analysis to support spatial differences in 2-AG synthesis and degradation. In embryonic cortices and thalami iso-

$\leftarrow$

(Figure legend continued.) photographed at E14.5 reveals $\mathrm{MGL}^{+}$axons in the trigeminal ganglion ( $5 \mathrm{Gn})$, submandibular trigeminal nerves ( $5 \mathrm{man})$, and spinal trigeminal tract $\left(\mathrm{sp} 5 ; \mathrm{C}_{2}\right)$, optic stalk (os), parabrachial/microcellular tegmental nuclei $\left(\mathrm{PB} / \mathrm{MiTg} ; \mathrm{C}_{3}\right)$, and thalamocortical (arrowheads) and olfactory tracts (1n). Open arrowheads indicate $\mathrm{MGL}^{+}$subventricular zone progenitors. $\boldsymbol{D}-\boldsymbol{D}_{4}, \mathrm{MGL}^{+}$TCAs course in the inferior thalamic radiation $\left(\boldsymbol{D}_{1}\right)$ before invading the cortical subplate $\left(\boldsymbol{D}_{2}\right.$, arrows). $\boldsymbol{D}_{1}, \mathrm{MGL}^{+}$axons at the anterodorsal thalamic boundary are intermingled with GABAergic neurons. $\boldsymbol{D}_{2}$, Radially migrating cortical neurons, presumed pyramidal cells, also express MGL. Note that GFP ${ }^{+}{ }^{G A B A e r g i c ~ i n t e r n e u r o n s ~ a r e ~} \mathrm{MGL}^{-}$at this developmental stage. $\boldsymbol{D}_{3}$, Brn- $^{+}{ }^{+}$/tau-EGFP ${ }^{+}$pyramidal cells (arrowheads) migrate through the $\mathrm{MGL}^{+}$subplate to reach their final positions. $\mathbf{D}_{4}, \mathrm{MGL}^{+}$puncta are in close apposition to tau-EGFP ${ }^{+}$cortical neurons (arrowheads). $E-E_{2}, M_{G L}{ }^{+}$axons populate the cortical IZ, hippocampal fimbria (f), lateral olfactory tract (lot), and optic nerves (och) by E16.5. Note that the striatal neuroepithelium (ne) lacks appreciable MGL expression. $\boldsymbol{F}_{,} \boldsymbol{F}_{1}$, By E18.5, MGL becomes restricted to neuronal perikarya and disappears from long-range axons. $\mathbf{G}$, Increased [2-AG] coincides with MGL redistribution by birth. ${ }^{*} p<0.05$ versus E14.5-E18.5 (Student's $t$ test). Open rectangles denote the location of insets. Abbreviations used in all figures are listed in the supplemental information (available at www.jneurosci.org as supplemental material). Scale bars: $A, A_{2}, C-C_{2}, D, E, F, 100 \mu \mathrm{m} ; A_{1}, D_{1}-D_{3}, 25 \mu \mathrm{m} ; D_{4}, E_{1}, E_{2}, F_{1}, 10 \mu \mathrm{m}$. lated at E16.5 $(n=4)$, we have found that MGL mRNA levels $(1.17 \pm 0.07$; unscaled normalized values throughout) significantly exceed those found in the cerebral cortex $(0.85 \pm 0.04)$ when normalized to GAPDH ( $p=0.009$ ) (Fig. $2 A$ ). Similarly, DAGL $\beta$ mRNA expression was also significantly higher in the thalamus $(1.09 \pm 0.03)$ than in the cerebral cortex $(0.81 \pm 0.05$; $p=0.003$ ) (Fig. 2B). Conspicuously, DAGL $\alpha$ coexists with DAGL $\beta$ at E16.5 (Fig. $2 C$ ) and exhibits similar regional variations $(0.95 \pm 0.02$ for thalamus vs $0.055 \pm 0.03$ for cortex; $p<0.001)$. In contrast, $\mathrm{CB}_{1} \mathrm{R}$ mRNA levels in the cerebral cortex exceed those in thalamus $(0.88 \pm 0.06$ for thalamus vs $1.08 \pm 0.05$ for cortex; $p=0.035)($ Fig. $2 D)$.

Next, we have performed qPCR analysis of primary cortical and thalamic neurons isolated at E16.5 and maintained for 4 DIV to validate subsequent cell biology studies (see Figs. 5-9) in cortical neurons endogenously expressing $\mathrm{MGL}, \mathrm{CB}_{1} \mathrm{R}$, and DAGLs. We show that both neuron populations maintain their cellular specificities of expressing molecular components of the 2-AG signaling cassette $(n=2)$ (Fig. $\left.2 A^{\prime}-D^{\prime}\right)$ compared with data obtained in vivo (Fig. $2 A-D$ ).

To further dissect whether expression of metabolic and receptor components of the 2-AG signaling system at the protein level is temporally coordinated, we analyzed pallial/cortical tissues (Fig. $2 E-E_{3}$ ) and subpallial/striatal specimens (supplemental Fig. 5, available at www.jneurosci.org as supplemental material) by Western blotting. We demonstrate that the $33 \mathrm{kDa}$ isoform of MGL is selectively expressed in embryonic brain tissue (Fig. 2E). Comparative analysis of this isoform from E14.5 to P1 supports 
our histochemical findings by revealing transiently decreased MGL protein levels at approximately E.18.5 [E18.5, $0.49 \pm 0.11$ vs P1 (cortex), $1.0 \pm 0.00$ (normalized); $p=0.010]$ (Fig. $2 E_{1}, E_{2}$ ) (supplemental Fig. $5 A_{1}, A_{2}$ ). In contrast, DAGL $\alpha$ expression peaks at E14.5/E16.5 with a dramatic decrease in DAGL $\alpha$ protein concentrations in neonates [E14.5, $14.41 \pm 6.21$ vs P1 (hippocampus), $0.96 \pm 0.34$ (values were normalized to P1 cortical levels); $p=0.044$ ] (Fig. $2 E_{1}, E_{2}$ ) (supplemental Fig. $5 A_{1}, A_{2}$, available at www.jneurosci.org as supplemental material). $\mathrm{CB}_{1} \mathrm{R}$ protein levels are essentially unchanged throughout forebrain development (Fig. $2 E_{1}, E_{3}$ ) (supplemental Fig. $5 A_{1}, A_{3}$, available at www.jneurosci.org as supplemental material).

CRIP1a can interact with the distal $\mathrm{C}$ terminus of $\mathrm{CB}_{1} \mathrm{R}$ (Niehaus et al., 2007) and may attenuate $\mathrm{CB}_{1} \mathrm{R}$-mediated inhibition of voltage-gated $\mathrm{Ca}^{2+}$ channels. However, the developmental expression profile of CRIP $1 \mathrm{a}$ in relation to $\mathrm{CB}_{1} \mathrm{Rs}$ is unknown. We show that CRIP1a protein levels (supplemental Fig. 1, available at www.jneurosci.org as supplemental material) are dynamically regulated in the developing nervous system with a progressive increase in cortical [E14.5, $0.57 \pm 0.27$ vs P1 (hippocampus), $1.24 \pm 0.28$ (normalized to CRIP1a levels in P1 cortex); $p=0.005$ ] (Fig. 2 $E_{1}, E_{3}$ ) and subpallial CRIP1a concentrations by birth [E14.5, $0.44 \pm 0.07$ vs P1, $1.0 \pm 0.00$ (normalized); $p=0.040$ ] (supplemental Fig. $5 A_{1}, A_{3}$, available at www.jneurosci.org as supplemental material). Overall, these experiments indicate that $2-A G$ metabolic enzymes and $\mathrm{CB}_{1} \mathrm{R}$ levels are controlled at both the mRNA and protein levels in vivo.

\section{$\mathrm{CB}_{1} \mathrm{Rs}$ in growth cones of cortical pyramidal neurons}

$\mathrm{CB}_{1}$ Rs have hitherto been demonstrated to accumulate in growth cones of GABAergic interneurons (Berghuis et al., 2007) as well as in the shaft of CFAs emanating from pyramidal cells (Berghuis et al., 2007; Vitalis et al., 2008). However, the presence of $\mathrm{CB}_{1} \mathrm{Rs}$ in motile growth cones of cortical pyramidal cells is ambiguous. We studied $\mathrm{CB}_{1} \mathrm{R}$ distribution at the ultrastructural level by correlated light and electron microscopy. We find that $\mathrm{CB}_{1} \mathrm{R}^{+}$axons are emitted earlier than thought previously ( $\leq$ E13) (Fig. $3 A$ ). $\mathrm{CB}_{1}$ Rs are distributed along the shafts and growth cones of CFAs that depart the cortical intermediate zone (IZ) and transit the internal capsule (Fig. $3 A, A_{1}$ ). $\mathrm{CB}_{1} \mathrm{R}^{+}$axons navigate in the neuropil of the internal capsule separately from each other (Fig. $\left.3 A_{1}\right)$. $\mathrm{CB}_{1}$ Rs are transported in small vesicles along the axon (Fig. $3 B$ ) and concentrate in motile filopodia that protrude at random from individual growth cones (Fig. $3 C, C_{1}$ ). Pathfinding decisions by $\mathrm{CB}_{1} \mathrm{R}^{+}$growth cones do not rely on the alignment of $\mathrm{CB}_{1} \mathrm{R}^{+}$ axons with each other as we detected using electron microscopy with three-dimensional reconstruction (Fig. $3 A_{2}, C, C_{1}$ ). Thus, $\mathrm{CB}_{1} \mathrm{R}$ expression during CFA tract formation is poised to allow eCBs to influence both the elongation and growth cone steering decisions of excitatory cortical efferents.

Our present and previous (Berghuis et al., 2007; Mulder et al., 2008) findings suggest that $C_{1}$ Rs are selectively expressed by cortical neurons, including pyramidal cells, and can affect the elongation and guidance of CFAs. We tested this notion by electroporating cortical pyramidal cells and thalamic projection neurons with an EGFP vector in utero. Our data demonstrate that $\mathrm{CB}_{1}$ Rs are present in CFAs coursing deep in the IZ (Fig. $3 D_{1}-d_{3}$ ) but absent from superficial TCAs (Fig. $3 E_{1}-e_{3}$ ). By using highresolution laser-scanning microscopy, we clearly show colocalization of pyramidal cell-derived EGFP and $\mathrm{CB}_{1} \mathrm{R}$ signals (Fig. $\left.3 d_{1}{ }^{\prime}-d_{3}{ }^{\prime}\right)$ while revealing a mutually exclusive distribution pattern of $\mathrm{CB}_{1}$ Rs and EGFP expressed by thalamic neurons (Fig. $\left.3 e_{1}{ }^{\prime}-e_{3}{ }^{\prime}\right)$. Overall, our results define the axonal specificity of $\mathrm{CB}_{1}$ Rs during corticogenesis.

\section{MGL and $\mathrm{CB}_{1}$ Rs are coexpressed in corticofugal but not thalamocortical axons}

The presence of MGL mRNA in the cerebral cortex suggests that MGL expression persists in developing cortical neurons. We examined MGL expression by cortical pyramidal cells by analyzing whether MGL colocalizes with $\mathrm{CB}_{1}$ Rs (Fig. 4A) that we have characterized as a specific pallial marker (Fig. $3 D_{3}$ ). Highresolution microscopy revealed that pyramidal cells populating the cortical plate at E16.5 harbor both MGL and $\mathrm{CB}_{1} \mathrm{R}$ immunoreactivities (Fig. $4 A_{1}$ ). Accordingly, $\mathrm{MGL}^{+} / \mathrm{CB}_{1} \mathrm{R}^{+}$axons populated the IZ of the cerebral cortex (Fig. $4 A_{2}$ ). We observed that $\mathrm{MGL}^{+}$axons are more numerous in the IZ than those containing $\mathrm{CB}_{1}$ Rs [area occupancy (percentage of region of interest), $31.7 \pm$ $3.0 \%\left(\mathrm{CB}_{1} \mathrm{R}^{+}\right)$vs $\left.68.4 \pm 3.0 \%\left(\mathrm{MGL}^{+}\right)\right]$(Fig. $\left.4 \mathrm{C}\right)$, with $6.7 \pm$ $1.3 \%$ of $\mathrm{MGL}^{+}$axons also containing $\mathrm{CB}_{1}$ Rs. Conversely, $13.1 \pm 2.0 \%$ of $\mathrm{CB}_{1} \mathrm{R}^{+}$axonal profiles harbored MGL immunoreactivity (Fig. $4 C_{1}$ ).

In the thalamus, however, $\mathrm{MGL}^{+}$axonal profiles were far more frequently encountered than $\mathrm{CB}_{1} \mathrm{R}^{+}$profiles [area occupancy (percentage of region of interest), $94.7 \pm 2.0 \%\left(\mathrm{MGL}^{+}\right)$vs $5.3 \pm 2.0 \%\left(\mathrm{CB}_{1} \mathrm{R}^{+}\right)$] (Fig. $\left.4 B-B_{1}{ }^{\prime \prime}, C\right)$. Only $1.0 \pm 0.1 \%$ of $\mathrm{MGL}^{+}$axons contained $\mathrm{CB}_{1} \mathrm{Rs}$, whereas $17.9 \pm 4.8 \%$ of $\mathrm{CB}_{1} \mathrm{R}-$ containing axonal profiles were dual labeled (Fig. $4 C_{1}$ ). The Pearson's correlation coefficient of dual-labeled structures did not differ from $R=0$, suggesting a lack of a direct relationship (coregulation) of $C_{1} R$ and $M G L$ levels in individual axonal profiles (Fig. $4 C_{2}$ ).

We found that $\mathrm{MGL}^{+}$and $\mathrm{CB}_{1} \mathrm{R}^{+}$axons are spatially segregated in the fimbria hippocampi (Fig. $4 D$ ). In fact, the fimbria can be subdivided into ventrolateral $/ \mathrm{CB}_{1} \mathrm{R}^{+}$, median/mixed, and dorsomedial/MGL ${ }^{+}$domains in coronal sections (Fig. $4 D_{1}-D_{3}$ ). We have confirmed this notion by quantitative morphometry showing inverse $\mathrm{MGL} / \mathrm{CB}_{1} \mathrm{R}$ colocalization probabilities in these domains (Fig. $4 D_{4}$ ). Together, these findings suggest that $\mathrm{CB}_{1} \mathrm{Rs}$ can coexist with MGL in CFAs. In contrast, the overwhelming majority of TCAs only contain MGL (Fig. 4E). Therefore, we suggest that TCAs can function as 2-AG-inactivating barriers to shape forward-facing 2-AG gradients, to minimize 2-AG "spillover" and to promote CFA pathfinding.

\section{$\mathrm{CB}_{1}$ Rs are indispensable for axon fasciculation but dispensable for DAGL $\alpha$ or MGL expression and axonal targeting}

The physiological outcome of eCB signaling is determined hierarchically by $\mathrm{CB}_{1}$ Rs being available at the cell surface (Hsieh et al., 1999), their differential recruitment of signal transduction pathways (Derkinderen et al., 2003), as well as the momentary metabolic balance between 2-AG synthesis (DAGL) and degrading (MGL) activities. Our present and previous data (Mulder et al., 2008) together establish that MGL is coexpressed and cotargeted with $\mathrm{CB}_{1}$ Rs and DAGLs in CFAs at midgestation. The coincident presence of enzymatic and receptor components of 2-AG signaling in CFAs allows us to address whether DAGL $\alpha$ and MGL expression and axonal targeting in fasciculating CFAs are linked to $\mathrm{CB}_{1} \mathrm{Rs}$. We tested this possibility in E16.5 $C B_{1} R^{-/-}$mice that exhibit enlarged CFA fascicles relative to their age-matched wildtype littermates (Mulder et al., 2008). We validated that $\mathrm{CB}_{1} \mathrm{R}$ activity in CFAs is indispensable for appropriately timed axonal elongation and fasciculation to occur as enlarged CFA fascicles 
can be seen in $C B_{1} R^{-/-}$mice when localizing both DAGL $\alpha$ and MGL (Fig. 5).

Next, we have explored whether the $\mathrm{CB}_{1} \mathrm{R}$ itself and/or the redundancy of signaling-competent 2-AG in the absence of its cognate receptor can affect DAGL $\alpha$ or MGL expression and CFA targeting. Neither DAGL $\alpha$ (Fig. $5 B-B_{1}{ }^{\prime}$ ) nor MGL (Fig. $5 C-C_{1}{ }^{\prime}$ ) expression in cortical territories is dependent on $\mathrm{CB}_{1} \mathrm{Rs}$. In fact, the bundled CFA phenotype in $C B_{1} R^{-/-}$mice amplifies the presence of both enzymes otherwise sparsely distributed in axons with parallel trajectories in wild-type cortices (Fig. $5 B_{1}{ }^{\prime}, C_{1}{ }^{\prime}$ ). Although we cannot exclude subtle alterations to the temporal control of DAGL and/or MGL expression or degradation in the absence of $C B_{1}$ Rs, our findings suggest that $\mathrm{CB}_{1} \mathrm{R}$ does not exert significant upstream control of DAGL $\alpha$ and MGL expression at midgestation.

\section{Mutually exclusive subcellular distribution of DAGL $\alpha$ and MGL in developing axons}

Any guidance cue or elongation factor requires a discrete subcellular niche, particularly the growth cone, in which temporally and spatially restricted ligandreceptor interactions can occur and translate into a growth response. eCB signaling has unique properties because this ligand family is lipophilic and can diffuse in biological membranes over significant distances (Chevaleyre et al., 2006) and exert their action, at least in part, through cellautonomous mechanisms (Mulder et al., 2008). We hypothesized therefore that 2 -AG synthesis by DAGL $\alpha / \mathrm{DAGL} \beta$ (Mulder et al., 2008) must exceed MGLdependent 2-AG degradation in axonal growth cones to generate 2-AG-rich hotspots for directional axonal growth. Individual axons developing in vitro provide a suitable model to assess this hypothesis by allowing precise, correlated localization of DAGLs and MGL as they elongate. Maturation of cortical neurons is not only characterized by the spatial expansion of their axons but also by the appearance of varicose structures (Dotti et al., 1988), with each varicosity recognized as a functionally active signaling entity.

In cortical cultures with elaborate yet immature axonal meshworks (4 DIV), DAGL $\alpha$ and MGL coexist in presynaptic varicosities (Fig. $6 A, A_{1}$ ). However, DAGL $\alpha$ is reduced in presynapse-like varicosities (Fig. $6 B$ ) once synaptogenesis concludes (Mulder et al., 2008). In contrast, MGL retains its presynaptic localization both within fasciculating axons (Fig. $6 C$ ) and $\mathrm{VAMP}^{+}$(synaptobrevin $2^{+}$) presynapses, whether autaptic or heterotaptic (Fig. $6 D, D_{1}$ ), thus recapitulating the
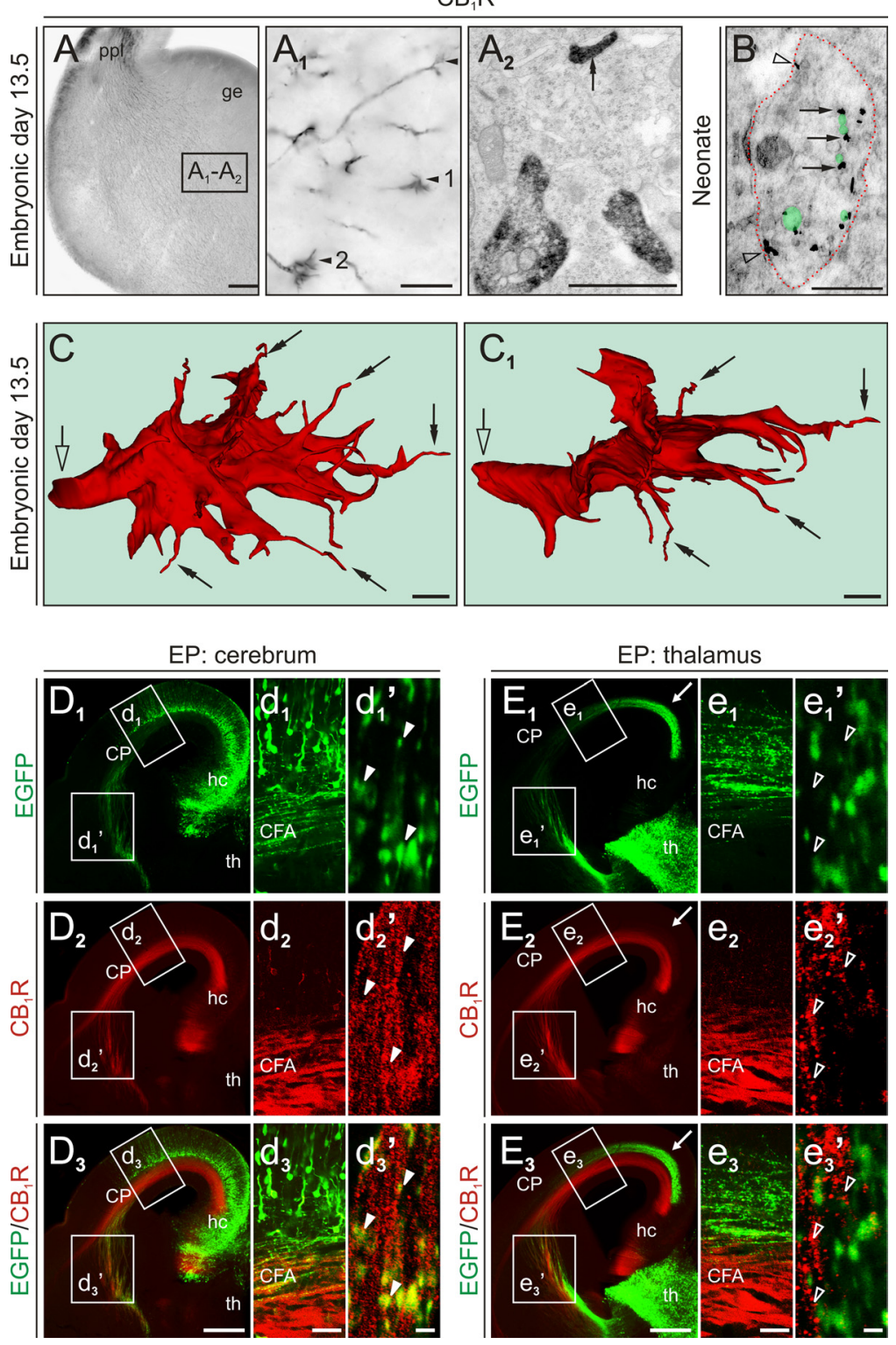

Figure 3. $C B_{1} R$ s in corticofugal afferents. $A, C B_{1} R^{+}$CFAs with their growth cones ( $\boldsymbol{A}_{1}$, arrowheads) transiting into the internal capsule by E13.5. Note that all axons grow in the same direction when departing the neocortex (left to right with neocortex being on the left; $\boldsymbol{A}_{1}$ ). $\boldsymbol{A}_{1}$ is a photomontage of light micrographs merged from different focal planes. Arrowheads $\boldsymbol{A}_{1}$ and $\boldsymbol{A}_{2}$ indicate growth cones that were analyzed using electron microscopy and subsequent three-dimensional reconstruction. $A_{2}$, Ultrastructural analysis of serial sections from a growth cone of a $C B_{1} R^{+}$corticofugal axon (identified as 1 in $A_{7}$ ) reveals anti-C $B_{1} R$ immunoperoxidase reaction end product in thick profiles and filopodial tips (double arrow). $\boldsymbol{B}$, In the neocortical intermediate zone, the axon shaft (cross-section profile is encircled with red dotted line) contains numerous $\mathrm{CB}_{1}$ Rs (visualized as silver-amplified immunogold particles; arrows) in small transport vesicles (highlighted semitransparent green) and on the plasmalemmal surface (open arrowheads). $C_{,} C_{1}$, Three-dimensional reconstruction of a growth cone reciprocally rotated $\sim 120^{\circ}$. Open arrows point to the truncated axon shaft. Note the numerous thin filopodia (double arrows) protruding in random directions. $\boldsymbol{D}_{\mathbf{1}}-\boldsymbol{E}_{3}$, Axons of EGFP-expressing cortical $\left(\boldsymbol{D}_{1}\right)$ but not thalamic neurons $\left(\boldsymbol{E}_{1}\right)$ are $\mathrm{CB}_{1} \mathrm{R}^{+}$at E16.5. In $\boldsymbol{E}_{\mathbf{1}}-\boldsymbol{E}_{3}$, arrow identifies EGFP ${ }^{+}$thalamocortical afferents residing in a spatially segregated $C B_{1} R^{-}$fascicle in the subplate. CFA labeling denotes the location of corticofugal axons in $\boldsymbol{d}_{1}-\boldsymbol{d}_{3}$ and $\boldsymbol{e}_{1}-\boldsymbol{e}_{3}$. Filled $\left(\boldsymbol{d}_{1}{ }^{\prime}-\boldsymbol{d}_{3}{ }^{\prime}\right)$ but not open $\left(\boldsymbol{e}_{1}{ }^{\prime}-\boldsymbol{e}_{3}{ }^{\prime}\right)$ arrowheads identify individual EGFP ${ }^{+} / \mathrm{CB}_{1} \mathrm{R}^{+}$axons of electroporated (EP) neurons. Scale bars: $\boldsymbol{D}_{3}, \boldsymbol{E}_{\mathbf{3}}, 500 \mu \mathrm{m} ; \boldsymbol{A}, \boldsymbol{d}_{3}, \boldsymbol{e}_{3}, 100 \mu \mathrm{m} ; \boldsymbol{A}, 10 \mu \mathrm{m} ; \boldsymbol{d}_{\mathbf{3}}{ }^{\prime}, \boldsymbol{e}{ }^{\prime}, 3 \mu \mathrm{m} ; \boldsymbol{A}_{1}, \boldsymbol{B}, 1 \mu \mathrm{m} ; \boldsymbol{A}_{2}, \boldsymbol{C}, \boldsymbol{C}_{1}, 0.5 \mu \mathrm{m}$.

distribution of MGL in adult brain (Dinh et al., 2002; Gulyas et al., 2004).

Subcellular analysis revealed that MGL accumulates in tubu$\mathrm{lin}^{+}$consolidating axon shafts with its levels tailing off toward the actin-rich motile axon tip leaving a "barrier region" of 9-12 $\mu \mathrm{m}$ with low MGL levels (termed "MGL delay" throughout) (Fig. $\left.6 E-E_{3}\right)$. To gain insights into the temporal dynamics of axonal 

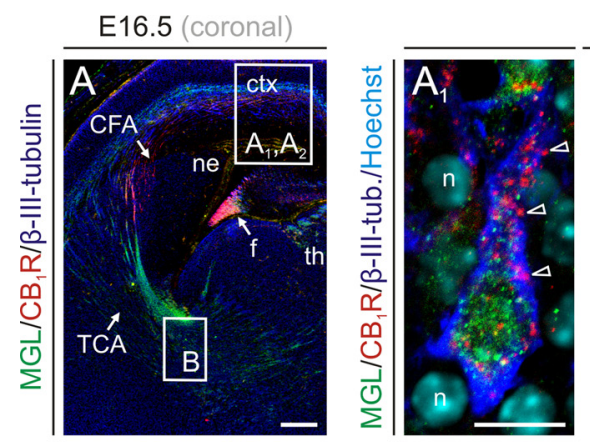

cerebral cortex

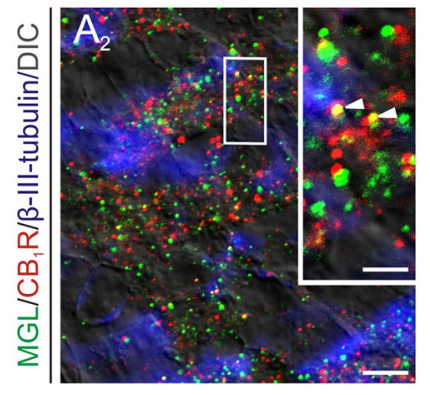

C

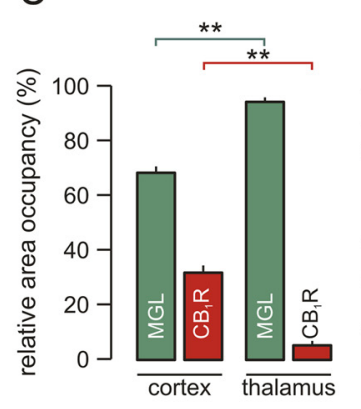

$\mathrm{C}_{1}$

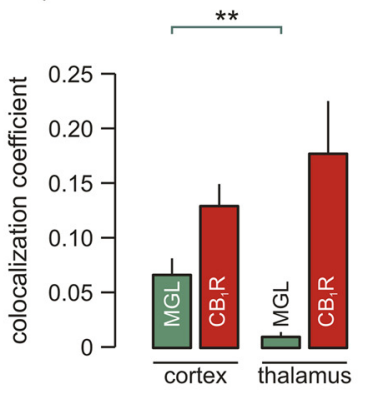

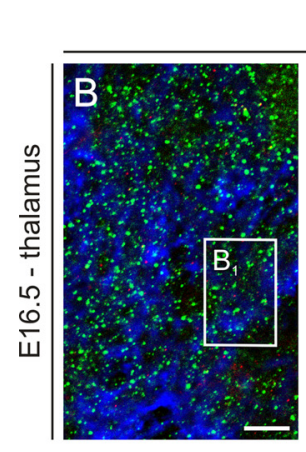

MGL/CB ${ }_{1}$ R/ß-III-tubulin/Hoechst
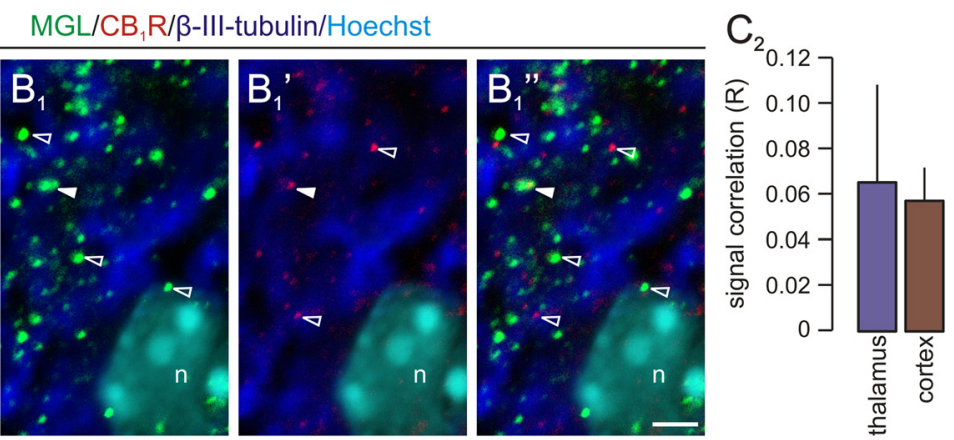
E $\cdot M G L$
- DAGLa
- $\mathrm{CB}_{1} \mathrm{R}$

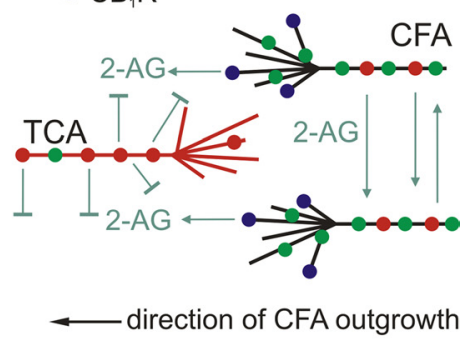

MGL/CB ${ }_{1} R / \beta$-III-tubulin/Hoechst/DIC
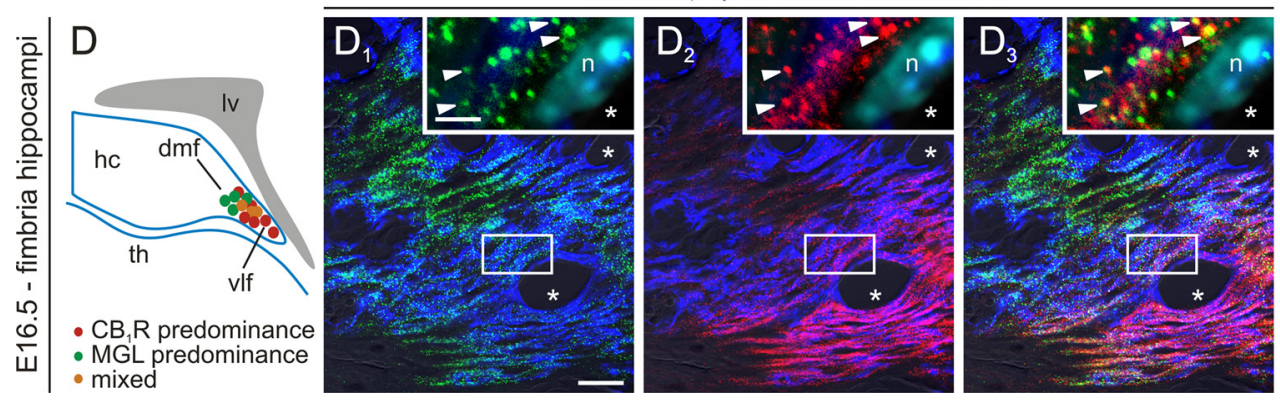

$\mathrm{D}_{4}$

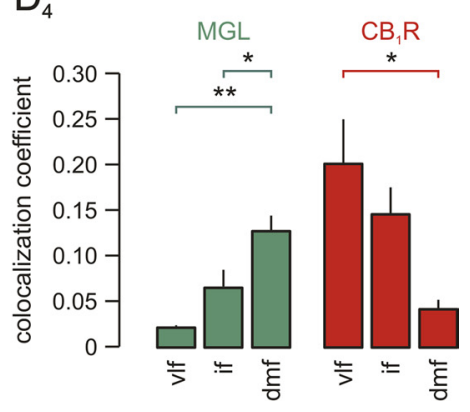

Figure 4. Differential colocalization of $\mathrm{CB}_{1}$ Rs and MGL in the cerebral cortex and thalamus. $A$, Both MGL and $\mathrm{CB}_{1} \mathrm{Rs}$ are present in long-range forebrain axons. $A_{1}$, Neocortical pyramidal cells are immunopositive for both MGL and $\mathrm{CB}_{1} R s . \boldsymbol{A}_{2}$, In the intermediate zone, a subset of axonal profiles are dual labeled for MGL and $\mathrm{CB}_{1} R . \boldsymbol{B}_{-} \boldsymbol{B}_{1^{\prime \prime}}, \mathrm{MGL}{ }^{+}$axons were found abundant, whereas $\mathrm{CB}_{1} \mathrm{R}^{+}$ axonal profiles were infrequently encountered in thalamic territories. $C$, Relative area coverage of $\mathrm{MGL}^{+}$and $\mathrm{CB}_{1} R^{+}$axons in the cerebral cortex and dorsal thalamus. $C_{1}$, Colocalization coefficients for MGL and $C_{1} R$ immunoreactivities reveal area-specific differences in their probability of colocalization. $C_{2}$, Pearson's correlation coefficient of $M G L / C B_{1} R$ approximates 0 in both brain regions studied. $\boldsymbol{D}$, The fimbria hippocampi comprises histochemical domains with distinct densities of $M G L^{+}$and $C_{1} R^{+}$axons. $D_{1}-D_{3}, M G L$ concentrates in the dorsomedial fimbria, whereas $C B_{1} R^{+}$ axonal profiles predominate in its ventrolateral extension. $\boldsymbol{D}_{4^{\prime}}$ Colocalization coefficients for $\mathrm{MGL}^{+}$and $\mathrm{CB}_{1} \mathrm{R}^{+}$axons in fimbrial subterritories. ${ }^{*} p<0.05,{ }^{* *} p<0.01$ (Student's ttest). $\boldsymbol{E}$, Working model of eCB-mediated CFA guidance with TCAs acting as ligand-inactivating barriers. Filled arrowheads denote colocalization, and open arrowheads show the lack thereof. Asterisks in $\left(\boldsymbol{D}_{1}-\boldsymbol{D}_{3}\right)$ mark blood vessels. Scale bars: $\boldsymbol{A}_{,} 500 \mu \mathrm{m} ; \boldsymbol{A}_{1}, \boldsymbol{A}_{2}, \boldsymbol{B}, \boldsymbol{D}_{1}, 12 \mu \mathrm{m} ; \boldsymbol{A}_{2}$ inset, $\boldsymbol{B}_{1}{ }^{\prime \prime}, \boldsymbol{D}_{1}$ inset, $3 \mu \mathrm{m}$.

MGL accumulation, we have compared the distribution of MGL at successive stages of axon development (Dotti et al., 1988). MGL is preferentially targeted to the quiescent axon once neuronal polarization occurs (Fig. 6E). Elongating axons retain MGL in their stable proximal segments (Fig. $6 E_{1}$ ) with a surprisingly steep decrement of MGL toward their actin ${ }^{+}$distal tip (Fig. $\left.6 E_{1}, E_{1}{ }^{\prime}\right)$. Compartmentalized MGL distribution is a fundamental hallmark of axon development and is independent of the morphology - whether bundled, spread, or looped (Morii et al., 2006) - of coexisting growth cones (Fig. $6 E_{2}-E_{3}{ }^{\prime}$ ). Notably, subcellular DAGL $\alpha$ and MGL localization is significantly different in motile growth cones with DAGL $\alpha$ but not MGL being present (Fig. $6 F, G$ ). In conclusion, DAGL $\alpha$ and MGL exhibit mutually exclusive distribution in motile neurites, in which the exclusion of MGL from the growth cone defines a subcellular niche for protrusive 2-AG signaling.
Proteasomal degradation is a candidate mechanism to exclude MGL from growth cones

The ubiquitin proteasome system (UPS) has been implicated in defining dynamic structural rearrangements during axonal growth (Haas and Broadie, 2008). Preferential UPS-mediated degradation of cytoskeletal and signalosome complexes underscores the continuous structural reorganization within the growth cone during its steering decisions (Campbell and Holt, 2001). The restricted localization of MGL to the immobile axon shaft led us to hypothesize that MGL degradation in the motile neurite tip could maintain the sensitivity of the growth cone to 2-AG. Bioinformatic tools (http://elm.eu.org) predict a destruction box motif (D-box) in MGL, suggesting that MGL could be degraded by the $20 \mathrm{~S}$ proteasome within the motile axon ending. We have experimentally tested whether compartmentalized proteasomal degradation contributes to the axonal gradient of MGL 

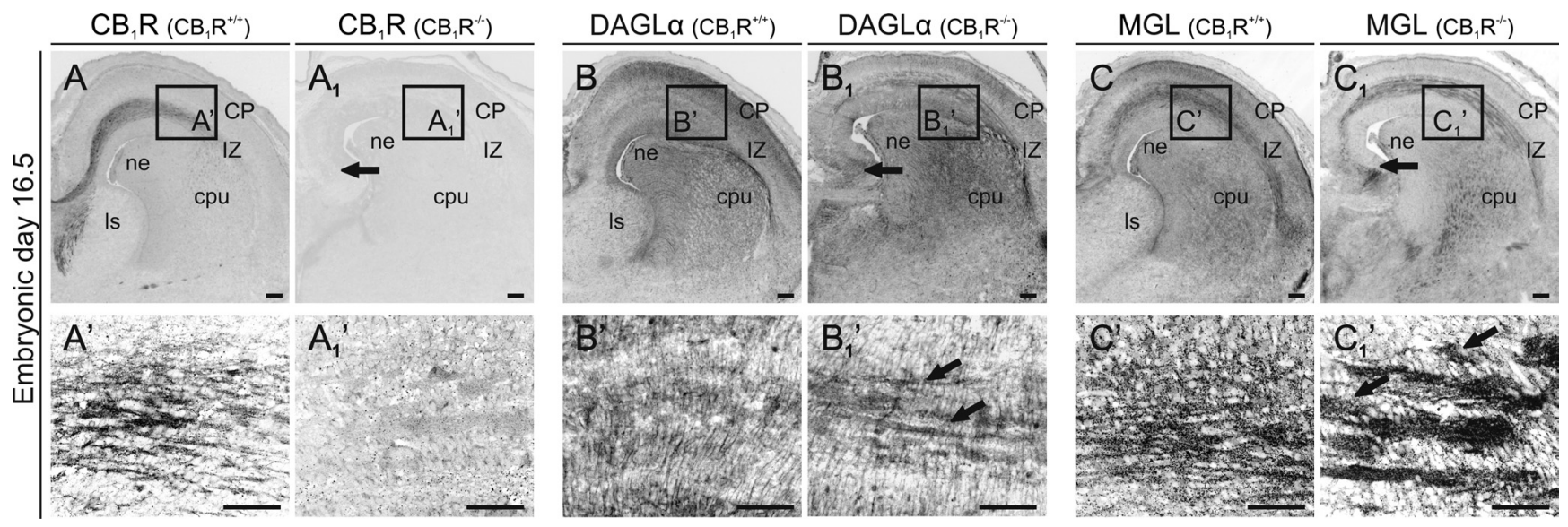

Figure 5. DAGL $\alpha$ and MGL expression in $C B_{1} R^{-/-}$telencephalon. $A_{1}\left(B_{1} R s\right.$ decorate corticofugal axons coursing in the cortical IZ and descending in fascicles through striatal patches. $A_{1}$, Axonal $\mathrm{CB}_{1}$ R immunoreactivity is entirely absent in $C B_{1} R^{-/-}$mice. $\boldsymbol{B}_{1} \boldsymbol{B}_{1}, \mathrm{DAGL} \alpha$ expression is essentially unchanged in $\left(B_{1} R^{-/-}\right.$brains in both the cerebral cortex and the hippocampal fimbria $\left(\boldsymbol{B}^{\prime}\right.$, arrow). At cellular resolution, DAGL $\alpha$ localizes to radial glia fibers and enlarged axon clusters in the $I Z$ of $C B_{1} R^{-/-}$mice $\left(\boldsymbol{B}_{1}{ }^{\prime}\right.$, arrows). $C_{1} \boldsymbol{C}_{1}$, Similarly, $\mathrm{CB}_{1} R$ deletion does not affect MGL expression in $\left(\boldsymbol{C}_{\boldsymbol{1}}\right)$ and targeting to ( $\boldsymbol{C}_{1}{ }^{\prime}$, arrows) axons in the cerebral cortex. Open rectangles identify the location of insets in $\boldsymbol{A}^{\prime}{ }^{\prime}-\boldsymbol{C}_{1}{ }^{\prime}$. Scale bars, $50 \mu \mathrm{m}$.

by exposing cortical neurons to lactacystin $(20 \mu \mathrm{M})$ to inactivate the catalytic site of the 20S proteasome (Omura et al., 1991). Because UPS inhibition affects the turnover of many proteins essential for neuronal survival or differentiation, we have established in vitro conditions in which UPS inhibition does not compromise cell viability (Fig. $7 E$ ) but affects MGL turnover (Fig. $7 A-C)$. We find that UPS inhibition disrupts MGL distribution such that MGL becomes indiscriminately present in the axon and dendrites (Fig. $7 B, C$ ) and ventures into growth cones (Fig. $\left.7 C_{2}, C_{3}\right)$. Fluorescence intensity distribution analysis of $\mathrm{MGL}^{+}$ axons revealed that UPS inhibition dissipates the spatial segregation of $\mathrm{MGL}^{+}$(established) and actin ${ }^{+}$(motile) axon segments (Fig. $7 D, E_{5}$ ). Ectopic MGL accumulation is observed in dendrites during lactacystin-induced disruption of MGL turnover (Fig. $\left.7 C, F-H_{1}\right)$.

If 2-AG hydrolysis by MGL impedes axonal growth, then disrupting the subcellular distribution of MGL will shorten axon length. Although an impaired UPS can increase the bioavailability of many proteins pivotal for axonal growth and thus disturb combinatorial signaling in growth cones, we argued that our model allows testing the premise that a molecular link between MGL stabilization in axons and discordant neurite outgrowth can exist. We find that UPS inhibition reduces the length of the lead neurite (Fig. $7 E_{1}$ ) and prunes both axon collateral complexity (Fig. $7 \mathrm{~B}, C, E_{2}$ ) and dendritogenesis (Fig. $7 H$ ) of cortical neurons. These findings suggest that MGL turnover is differentially regulated in the motile and consolidated axon segments and can affect axonal elongation.

\section{Synaptogenesis disrupts the axonal MGL microgradient}

Although MGL primarily avoids the motile neurite segment, it accumulates in presynapses of cultured neurons (Fig. 8) as well as many presynaptic terminals of the adult cerebral cortex (Dinh et al., 2002; Gulyas et al., 2004; Kano et al., 2009). This presents the possibility that MGL redistribution in the growth cone is physiologically relevant to decrease the velocity of 2-AG-induced motility when a growth cone approaches its postsynaptic target. Therefore, we have determined whether subcellular MGL distribution changes during synaptogenesis. We find that MGL accumulates in growth cones that appose a postsynaptic neuron in vitro (Fig. $8 A-B_{3}$ ) (supplemental Fig. $6 A, D-D_{2}$, available at www.jneurosci.org as supplemental material). In contrast, growth cones of axon collaterals who have not selected a target remain $\mathrm{MGL}^{-}$(Fig. 8A) (supplemental Fig. 6A-C ${ }_{2}$ ). These data suggest that the axonal polarity of MGL dissipates and MGL can limit 2-AG signaling as a growth cone engages in its postsynaptic target selection (Fig. 8C, $C_{1}$ ).

\section{MGL inhibition induces axonal growth}

Although evidence is accumulating that $\mathrm{CB}_{1}$ Rs affect (in isolation or synergistically with other receptors) axonal growth and steering decisions, evidence on the molecular identity of the eCB required for axonal growth is still lacking. Our findings could imply that 2-AG may function as an axonal elongation signal. We tested this possibility by inhibiting the enzymatic activity of MGL with JZL184 (100 nM), a selective MGL inhibitor (Long et al., 2009). Exposure to JZL184 (16 h) invariably triggers neurite outgrowth in both cells that emit a stunted quiescent axon shortly after plating (Fig. 9A-B $B_{2}$ ) and neurons with an established primary neurite in vitro (Fig. $9 C-C_{2}$ ). We have confirmed these data by applying URB $602(5 \mu \mathrm{M})$, an alternative MGL inhibitor (King et al., 2007), whose application also increases axonal growth (data not shown). Notably, MGL inhibition regulates neither the length of the actin ${ }^{+}$distal neurite segment (Fig. $9 B_{2}, C_{2}$ ) nor compartmentalized MGL distribution (data not shown) in axons, thus suggesting that MGL inactivation does not directly influence MGL degradation.

Overall, our data suggest that MGL exerts dual functions during axonal growth: MGL may form an intracellular barrier keeping lipophilic 2-AG from diffusing retrogradely from the growth cone in the axonal plasma membrane to prematurely engage $\mathrm{CB}_{1}$ Rs and induce ectopic growth responses (Fig. 8C, $C_{1}$ ). In addition, the exclusion of MGL from the motile neurite tip could allow for cell-autonomous or target-derived 2-AG to selectively impact the growth cone and trigger axonal elongation in a coordinated manner.

2-AG is one of the many potential targets of MGL in vivo (Nomura et al., 2010). It is therefore possible that MGL hydrolyzes a ligand distinct from 2-AG to regulate axonal elongation. To exclude this possibility, we treated neurons with JZL184 in combination with O-3841 or THL, DAGL inhibitors. We show that coincident blockade of MGL and DAGL activities by JZL184 and either O-3841 [104.2 $\pm 6.7 \mu \mathrm{m}$ (JZL184, $n=39)$ vs $80.4 \pm$ $4.9 \mu \mathrm{m}$ (JZL184 + O-3841, $n=40) ; p=0.005$ ] (Fig. $\left.9 D-D_{2}, F_{1}\right)$ or 


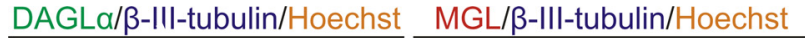
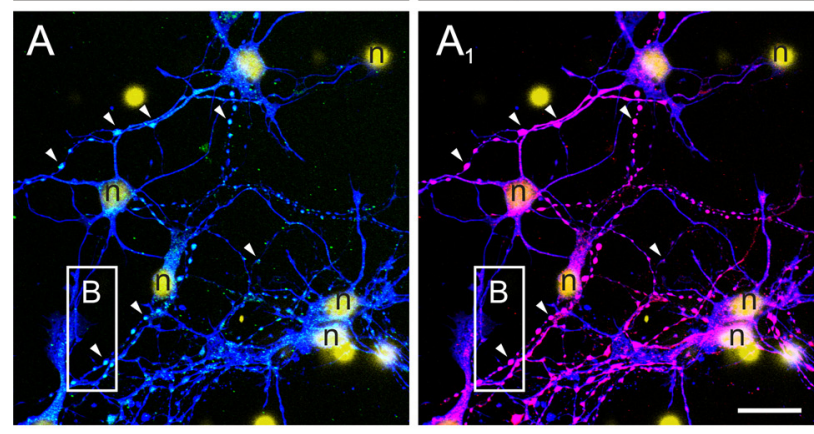
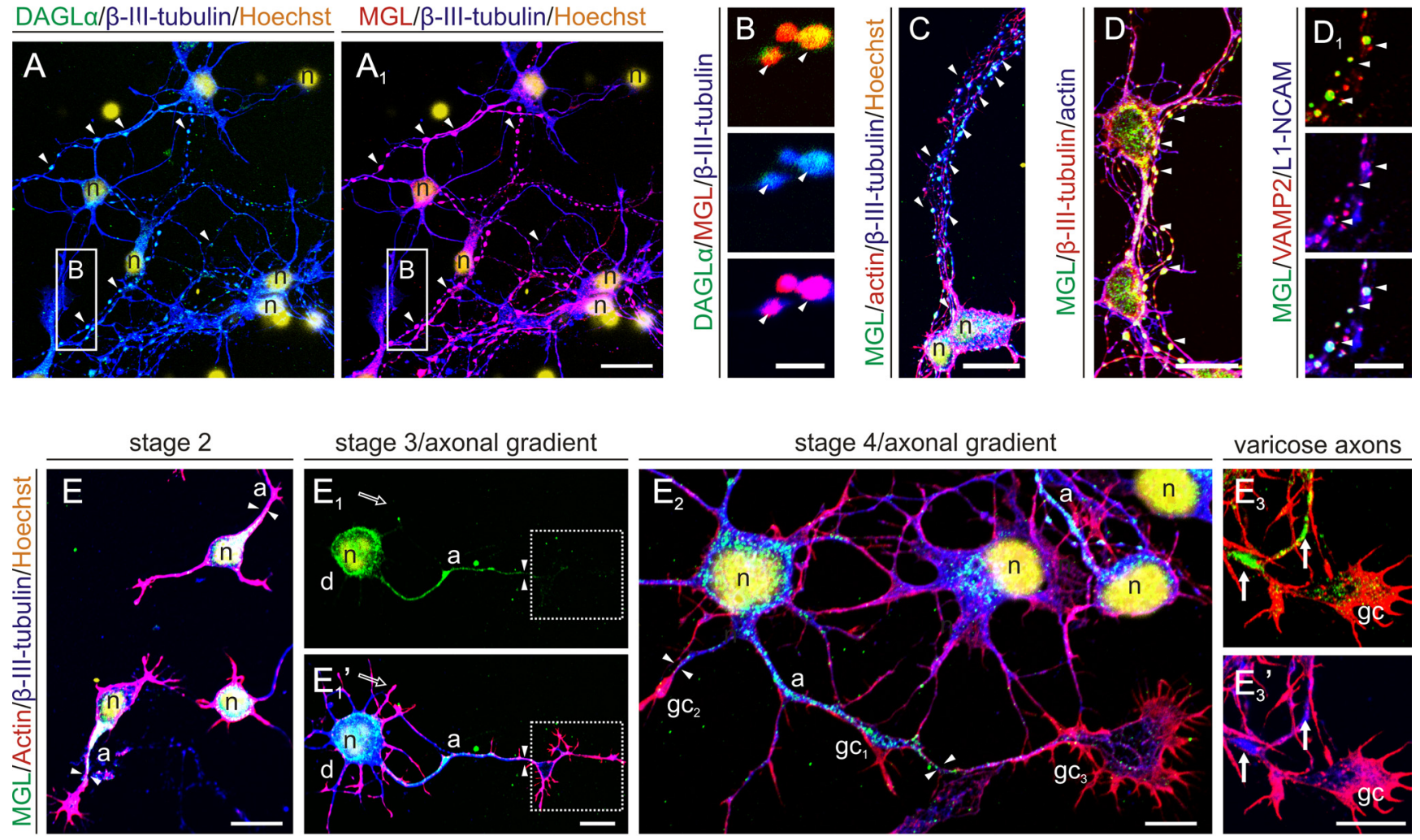

stage 3/axonal gradient
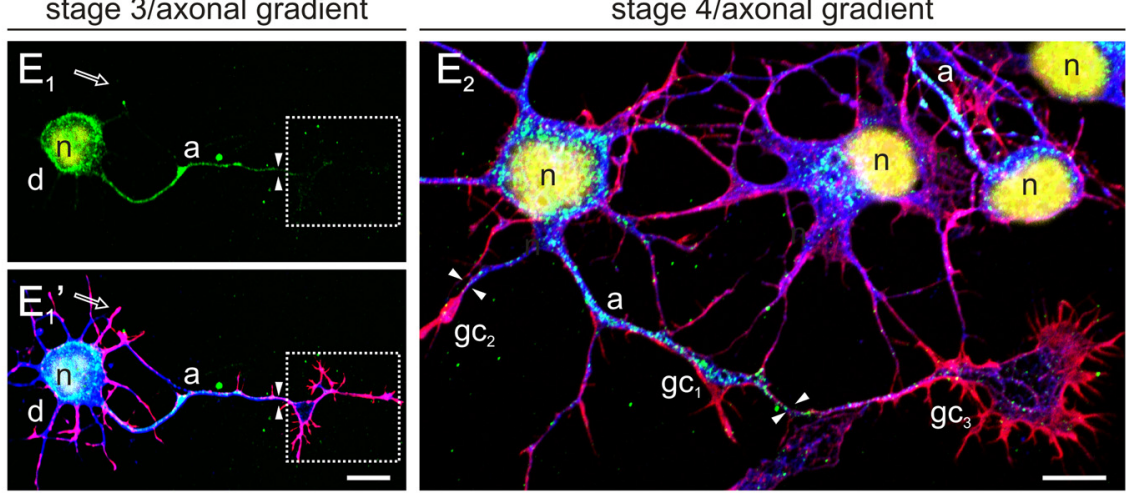

varicose axons

MGL/DAGLa/ß-III-tubulin/DIC
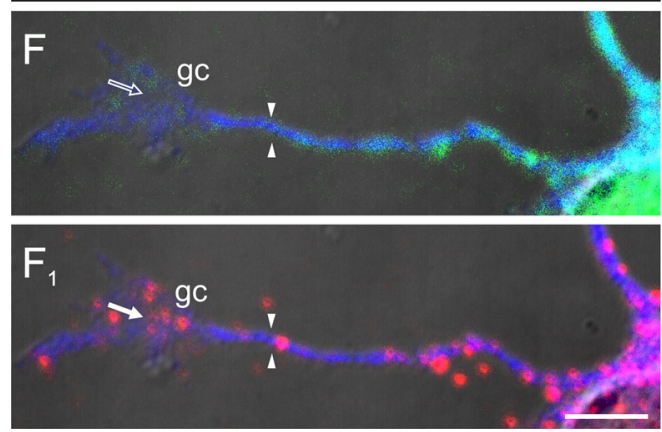

G

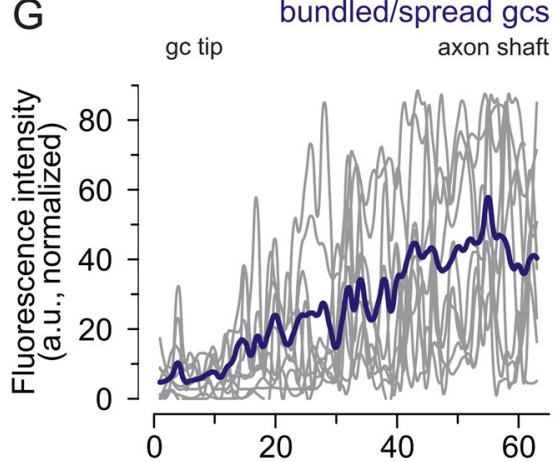

gc tip

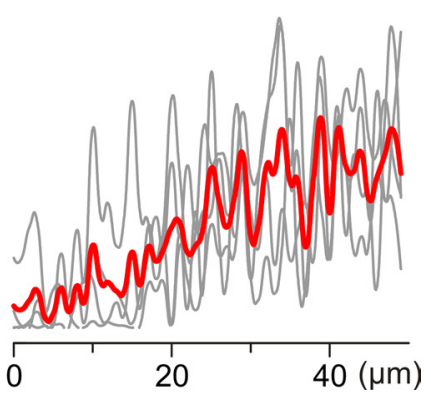

Figure 6. Differential subcellular targeting of DAGL $\alpha$ and MGL during axon development. $A, A_{1}$, In primary cortical cultures, DAGL $\alpha$ and MGL are cotargeted to growing axons and often coexist in stable varicosities ( $\boldsymbol{B}$, arrowheads). During axon fasciculation ( $\boldsymbol{C}$ and postsynaptic targeting $(\boldsymbol{D})$, DAGL $\alpha$ (Bisogno et al., 2003) but not MGL (arrowheads) is eliminated from axons and presynapses. $\boldsymbol{D}_{1}$, VAMP2 (synaptobrevin 2) was used to visualize presynaptic specializations. $E$, MGL is selectively trafficked into the quiescent premature axon (a) and accumulates in its proximal segment as soon as neuronal polarization commences. In neurites with looped growth cones $\left(\boldsymbol{E}_{1}\right)$, fluorescence signal separation reveals mutually exclusive distribution of actin and MGL in motile axons (a; open rectangle) or dendrites (d). $\boldsymbol{E}_{2}$, MGL microgradients are invariably present in coexisting neurites with bundled $\left(g c_{1}\right)$, spread $\left(g c_{2}\right)$, or looped $\left(g c_{3}\right)$ growth cones. $E_{3}, E_{3}{ }^{\prime}$, The presence of MGL in established axon segments and presynapse-like varicosities (arrows) is maintained in elaborate axonal meshworks in vitro. $\boldsymbol{F}_{1} \boldsymbol{F}_{1}$, Subcellular MGL and DAGL $\alpha$ targeting is strikingly different, with MGL being primarily excluded from the motile neurite tip (arrow). Arrowheads indicate the transition point between $\mathrm{MGL}^{+}$and $\mathrm{MGL}^{-}$domains. G, MGL immunofluorescence intensity measured in individual bundled/spread (left) or looped (right) growth cones (gcs) and adjoining distal axon segments. Individual fluorescence intensity plots are in gray, and average values are in blue/red. Scale bars: $A-C_{1}, D_{1}, F-G_{1}, 10 \mu \mathrm{m} ; \boldsymbol{E}, 3 \mu \mathrm{m}$.

THL $[104.2 \pm 6.7 \mu \mathrm{m}(\mathrm{JZL} 184, n=39)$ vs $64.5 \pm 4.3 \mu \mathrm{m}$ (JZL184 + THL, $n=32) ; p<0.001$ ] abolishes the JZL184-induced growth response. We verified that the effect of $2-\mathrm{AG}$ is mediated by $\mathrm{CB}_{1}$ Rs by showing that $\mathrm{O}-2050$, a neutral $\mathrm{CB}_{1} \mathrm{R}$ antagonist, significantly attenuates JZL184-induced neurite extension [104.2 \pm $6.7 \mu \mathrm{m}(\mathrm{JZL} 184, n=39)$ vs $84.3 \pm 6.6 \mu \mathrm{m}$ (JZL184 + O-2050, $n=35) ; p=0.036$ ] (Fig. $9 D_{1}$ vs $D_{3}, F_{1}$ ). Neuronal morphology was not compromised by any of the drugs used, as reflected by an unchanged number of processes (Fig. $9 F_{2}$ ).

Endocannabinoids have been shown to induce repulsive growth cone turning by activating RhoA GTPases (Berghuis et al., 2007). A repulsive response of motile growth cones will invariably couple to axonal elongation because directional growth is required to avoid the chemorepulsive cue. This phenomenon can also exist when ligands are indiscriminately present in culture media, as in our model, with the outcome being structural rearrangements within the growth cone and chaotic axonal elongation. Therefore, determining the growth cone size will reveal whether surplus 2-AG impacts growth cone morphology in neurons deficient in MGL activity. Growth cones of cortical pyramidal cells retained chaotic filopodial complexity in vitro (Fig. 9E $E_{1}$ ) and in vivo (Fig. 3C). JZL184 induced a growth cone phenotype reminiscent of immature motile neurite tips [surface size, $8.57 \pm$ $1.16 \mu \mathrm{m}^{2}$ (JZL184, $\left.n=24\right)$ vs $15.78 \pm 1.55 \mu \mathrm{m}^{2}$ (control, $n=$ 33); $p<0.001$ ] (Fig. 9G) possessing a lead filopodium (Fig. $9 E_{2}$ ). O-3841 [surface size, $15.92 \pm 2.00 \mu \mathrm{m}^{2}(n=25) ; p=0.003$ vs 

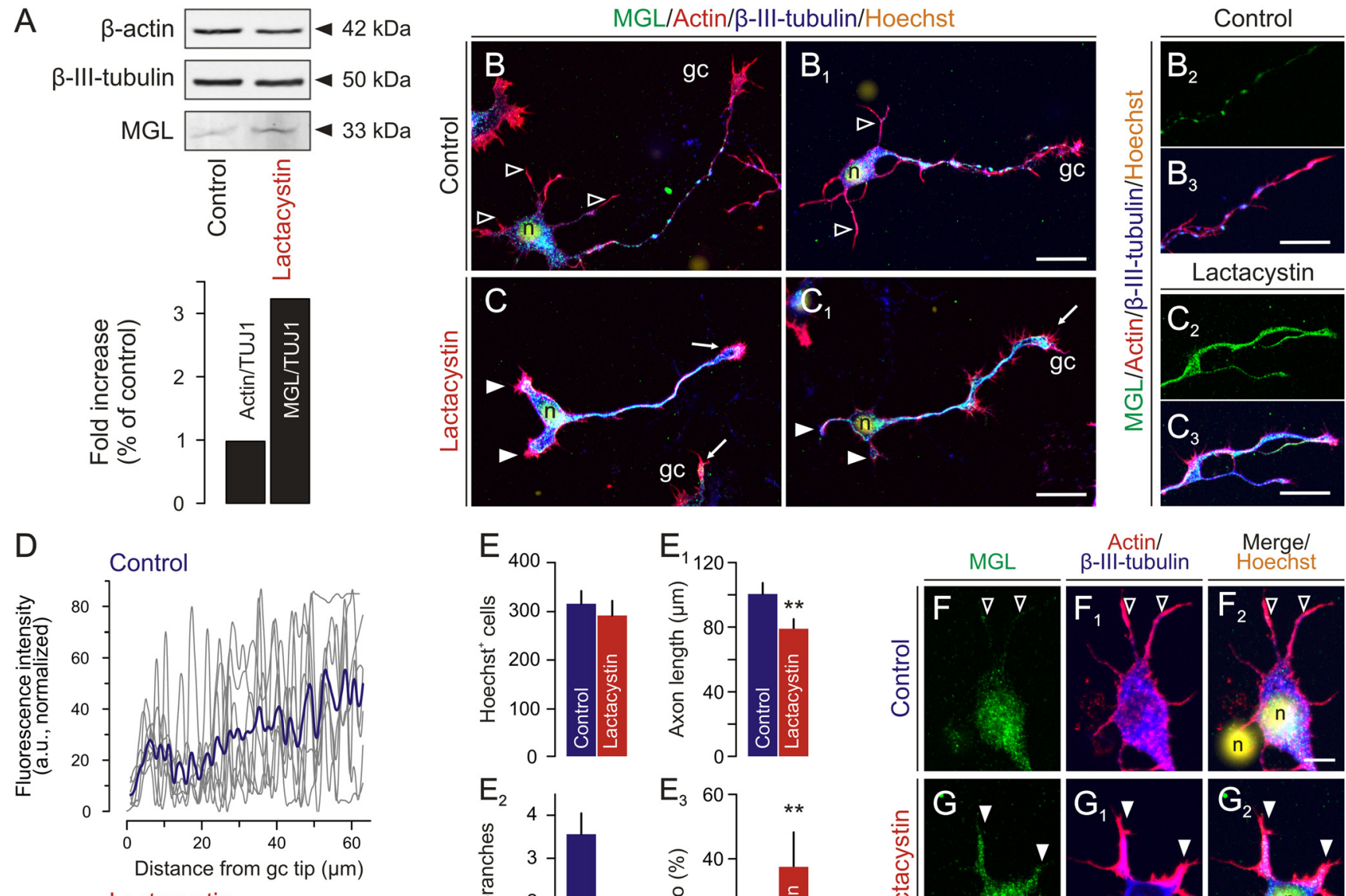

Actin/

Merge/
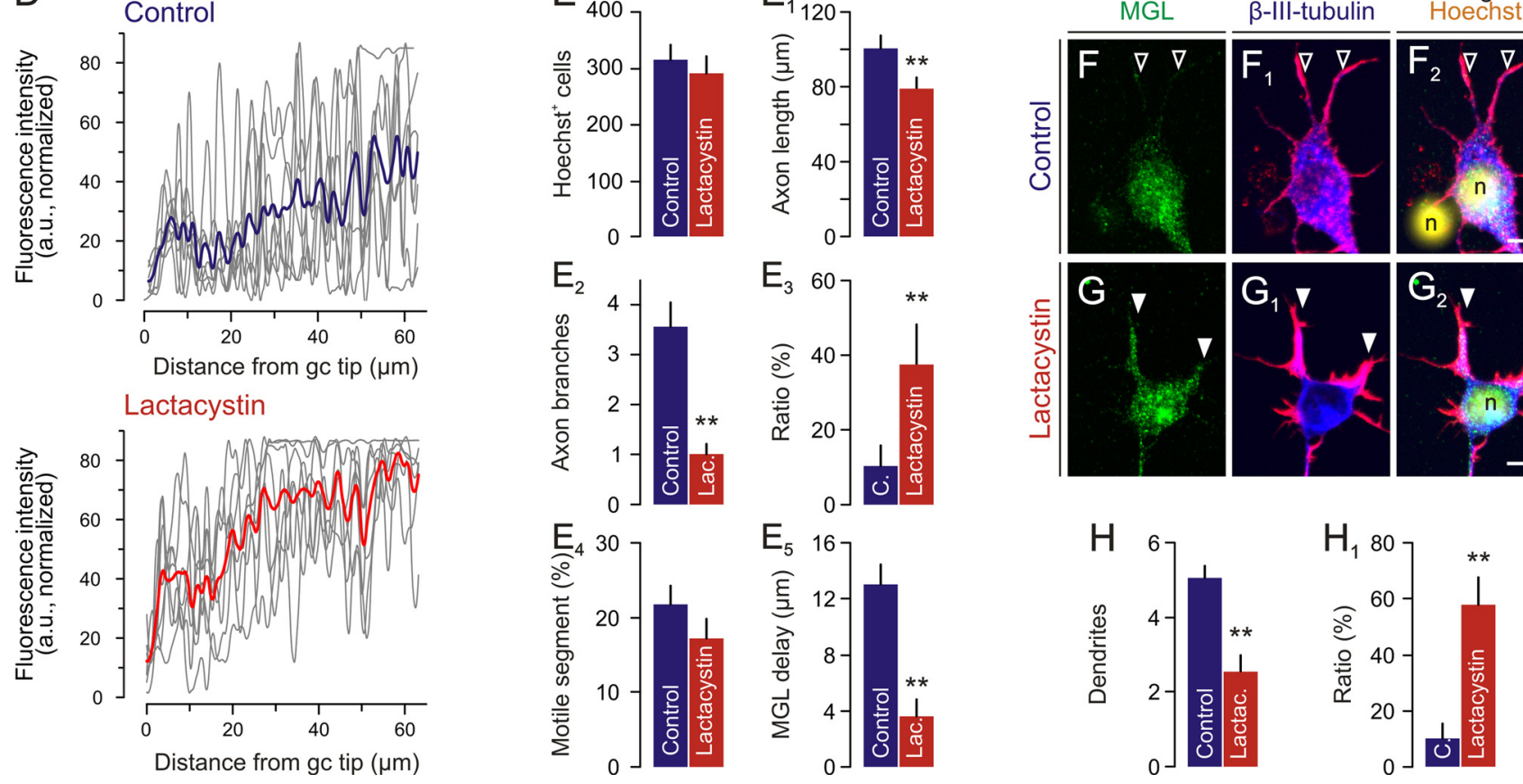

Figure 7. Proteasomal degradation excludes MGL from the motile neurite segment. $A$, Lactacystin increases MGL levels in primary cortical neurons. $\beta$-III-Tubulin (Tuj1) was used as loading control. Lactacystin stabilizes MGL in thelead neurite and eliminates its microgradient $\left(\boldsymbol{C}_{,} \boldsymbol{C}_{\boldsymbol{T}}\right)$ otherwise seen in control cells $\left(\boldsymbol{B}, \boldsymbol{B}_{\boldsymbol{1}}\right.$; see also $\left.\boldsymbol{E}_{5}\right)$. Lactacystin disrupts axonal $M G L$ targeting with stabilized $M G L$ accumulating in both axonal (arrows) and dendritic (arrowheads) growth cones. $\boldsymbol{B}_{2}-\boldsymbol{C}_{3}$, MGL distribution in motile axon segments at high resolution. $\boldsymbol{D}$, Fluorescence intensity plots reveal that proteasome inhibition significantly increases axonal MGL content. Individual and average fluorescence intensity plots are depicted in gray and blue/red colors, respectively. $\boldsymbol{E}$, Lactacystin (24h) does not compromise neuronal viability. However, lactacystin decreased the rate of axonal elongation $\left(\boldsymbol{E}_{1}\right)$, inhibits axonal branching $\left(\boldsymbol{E}_{2}\right)$, and increases the number of $\mathrm{MGL}^{+}$axon collaterals $\left(\boldsymbol{E}_{3}\right)$ without shortening or collapsing the motile neurite tip $\left(\boldsymbol{E}_{4}\right)$. Lactacystin also suppressed dendritogenesis $(\boldsymbol{F}-\boldsymbol{H})$ and stabilized MGL ventures into proximal dendrites $\left(\boldsymbol{G}-\boldsymbol{G}_{2}\right.$, arrowheads, $\left.\boldsymbol{H}_{\boldsymbol{1}}\right) .{ }^{* *} p<0.01$ (Student's test); $n=15-20$ cells per group. Scale bars: $\boldsymbol{B}_{1}$, $C_{1}, 20 \mu \mathrm{m} ; B_{3}, C_{3}, F_{2}, G_{2}, 10 \mu \mathrm{m}$.

JZL184] (Fig. $\left.9 E_{3}, G\right)$ but not THL ( $p=0.738$ vs JZL184) (Fig. $9 G$ ) significantly reduced JZL184-induced growth cone remodeling. Similarly, $\mathrm{CB}_{1} \mathrm{R}$ blockade by O-2050 markedly impeded the JZL184-induced reduction of growth cone size [surface size, $12.36 \pm 1.81 \mu \mathrm{m}^{2}(n=26) ; p=0.085$ vs JZL184] (Fig. $\left.9 G\right)$. In summary, our data reconcile that $2-\mathrm{AG}$ can act as both a directional cue (Berghuis et al., 2007) and an elongation factor while sculpting axonal complexity.

\section{Discussion}

MGL in the developing nervous system

The prevailing view that eCBs, particularly 2-AG, exert many functions in the developing nervous system is underscored by a rapidly expanding cohort of experimental studies demonstrating eCB-dependent neural progenitor self-renewal and neurogenic commitment (Aguado et al., 2005, 2006; Goncalves et al., 2008), long-range as well as local neuronal migration (Berghuis et al., 2005; Morozov et al., 2009) and synaptogenesis (Berghuis et al., 2007). eCB signaling is likely to coexist and cooperate with signaling cascades indispensable for neuronal identification, including neurotrophins (Maison et al., 2009) and chemokines (Zorina et al., 2010). Compelling evidence indicates that both DAGLdependent 2-AG synthesis and $\mathrm{CB}_{1} \mathrm{R}$-dependent signal transduction are under cell-state-specific regulatory control of BDNF (Maison et al., 2009) and FGF receptor signaling cascades (Williams et al., 2003). It is not surprising therefore that $\mathrm{CCB}$ actions underpin- 


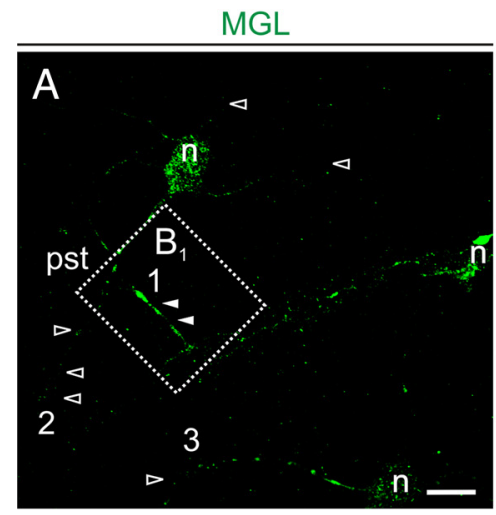

MGL/Actin/ß-III-tubulin/Hoechst
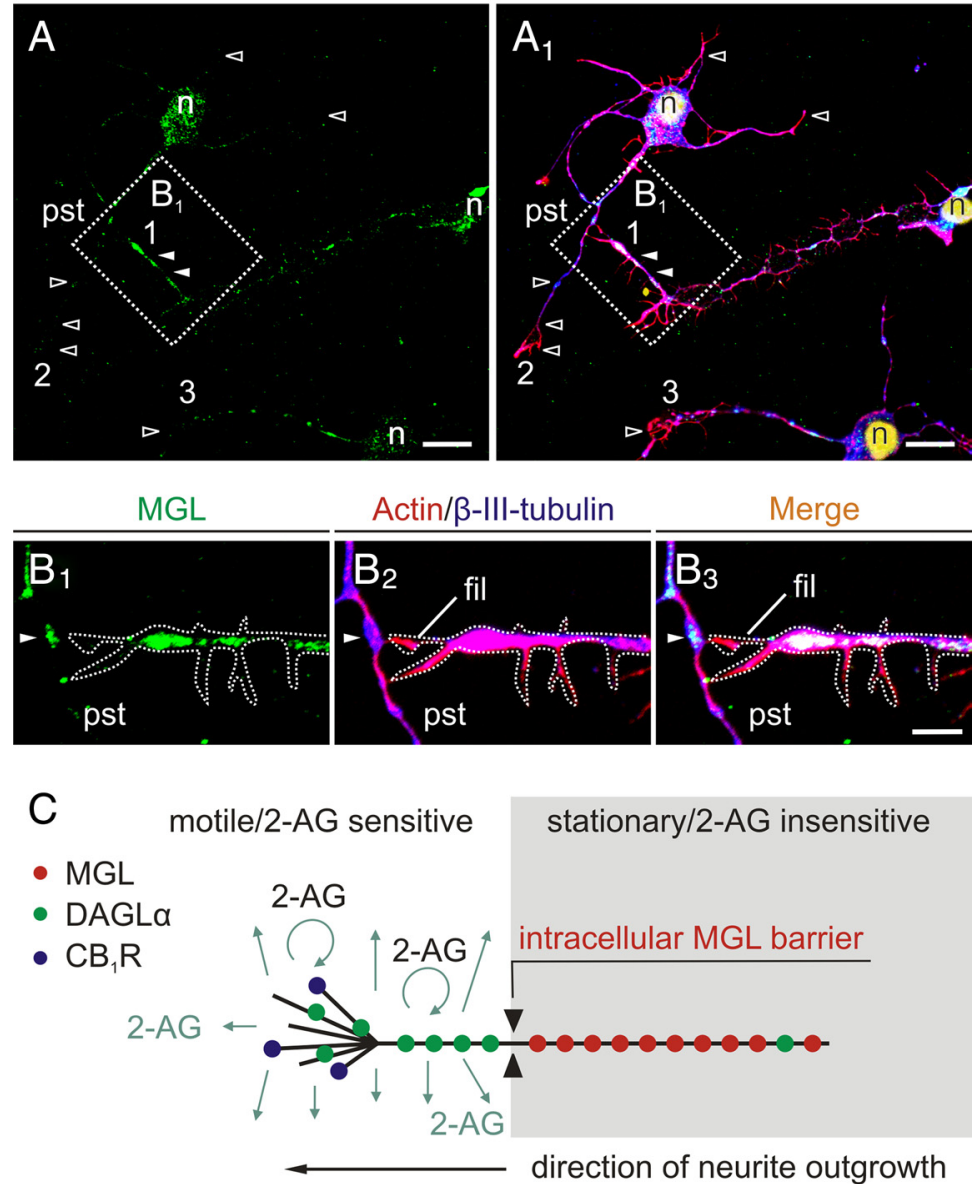

$\mathrm{C}_{1}$

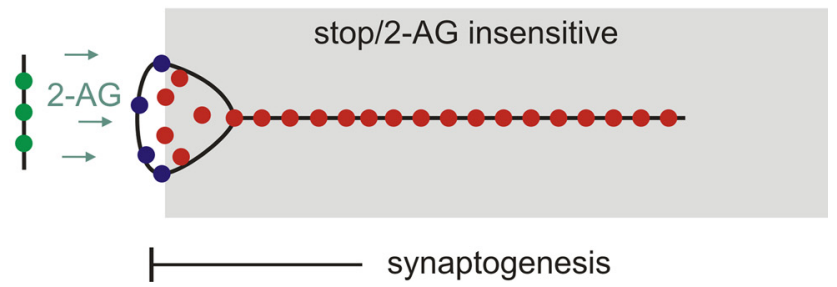

Figure 8. Synaptogenesis coincides with subcellular MGL redistribution. $A, A_{1}$, Postsynaptic target selection coincides with MGL redistribution along the axon and the growth cone (1; arrowheads). In the meantime, motile axon collaterals lack MGL ( 2 and 3; open arrowheads). Open rectangle indicates the position of $\boldsymbol{B}_{\boldsymbol{1}}-\boldsymbol{B}_{3}$, showing MGL being present in the central growth cone domain but not filopodia (fil) as well as in a putative postsynaptic target (pst; arrowhead). Working model of the developmental functions of MGL ( $\boldsymbol{C}$ ) and its redistribution during synapse formation $\left(\boldsymbol{C}_{\boldsymbol{1}}\right)$. Scale bars: $\boldsymbol{A}, \boldsymbol{A}_{1}, 20 \mu \mathrm{m} ; \boldsymbol{B}_{3}, 2 \mu \mathrm{m}$.

ning neuronal diversification and axonal growth are precisely timed and spatially coordinated in the developing brain (Bisogno et al., 2003). The precision of $2-A G$ signaling in a neurodevelopmental context is emphasized by the translocation of DAGLs from axonal tracts once synaptogenesis concludes (Bisogno et al., 2003) to dendritic spines apposing mature presynapses to maintain retrograde signaling (Katona et al., 2006; Yoshida et al., 2006). 2-AG degradation by MGL, and probably also by ABHD6 and ABHD12 lipases (Blankman et al., 2007; Hashimotodani et al., 2007; Straiker et al., 2009), is critical to maintain the temporal dynamics of retrograde synaptic communication and the sensitivity of presynaptic $\mathrm{CB}_{1}$ Rs to activity-dependent transient peaks of extracellular 2-AG concentrations. It is therefore physiologically necessary to place MGL into the presynapse (Gulyas et al., 2004) in which it can rapidly terminate 2-AG signaling (Hashimotodani et al., 2007).
Dynamic subcellular recruitment of both metabolic and receptor components of 2-AG signaling networks in the developing nervous system is achieved through cell-autonomous programming of both the expression and subcellular sorting of DAGLs, MGL, and $\mathrm{CB}_{1}$ Rs. We find that MGL is coincidently expressed with $\mathrm{CB}_{1}$ Rs and DAGLs by E12 in mouse, thus providing critical hydrolytic activity to terminate undesired 2-AG actions when the telencephalic SVZ progenitor pool begins to expand. The differential recruitment of MGL to distinct subcellular domains of neurons, particularly the consolidated axon shaft, provides an appealing candidate for the cell-autonomous regulation of 2-AG-dependent positional activation of $\mathrm{CB}_{1}$ Rs. In fact, neurons can spatially confine their 2-AG-inactivating enzymatic capacity intracellularly such that $\mathrm{CB}_{1}$ Rs are kept inactive while undergoing vesicular transport along the axon even in the presence of membranediffusible 2-AG. Because agonist activation of $\mathrm{CB}_{1}$ Rs can result in surplus neurite branching in vitro (Mulder et al., 2008), the molecular arrangements we uncovered suggest that MGL activity in the immotile axon shaft is required and sufficient to prevent discordant signaling events that could manifest in ectopic branching and axon guidance errors.

Transient removal of MGL from axonal tracts during the perinatal period (E18.5 to P2) may have intriguing physiological implications. The arrest of MGL in neuronal perikarya and dendrites coincides with a previously reported, yet unexplained, peak (up to $\sim 9 \mathrm{ng} / \mathrm{g}$ tissue) in perinatal tissue 2-AG levels (Berrendero et al., 1999). Our analysis significantly extends these observations by showing that 2-AG levels are increased as a result of a transient lack of 2-AG hydrolysis capacity in the neonatal hippocampus (up to $\sim 45$ $\mathrm{ng} / \mathrm{g}$ tissue) with minor changes in other brain regions. We suggest that the neonatal 2-AG peak in the hippocampus can provide a mechanism to mute synaptic information processing, thus preventing memory formation during delivery.

An 1000-fold excess of tissue 2-AG concentrations over those of AEA exists in the fetal brain (Berrendero et al., 1999). This observation together with our detailed understanding of the metabolic network controlling 2-AG bioavailability (Bisogno et al., 2003; Nomura et al., 2010) prompted the molecular dissection of neurodevelopmental 2-AG signaling. Nevertheless, in vitro data (Aguado et al., 2005; Berghuis et al., 2005; Mulder et al., 2008) convincingly demonstrate that AEA can also elicit physiologically relevant $\mathrm{CB}_{1} \mathrm{R}$-mediated responses in developing neurons. AEA may also be involved in fine-tuning 2-AG bioavailability (Maccarrone et al., 2008). Hence, we expect future studies to unravel AEA-specific signaling events and add an ad- 

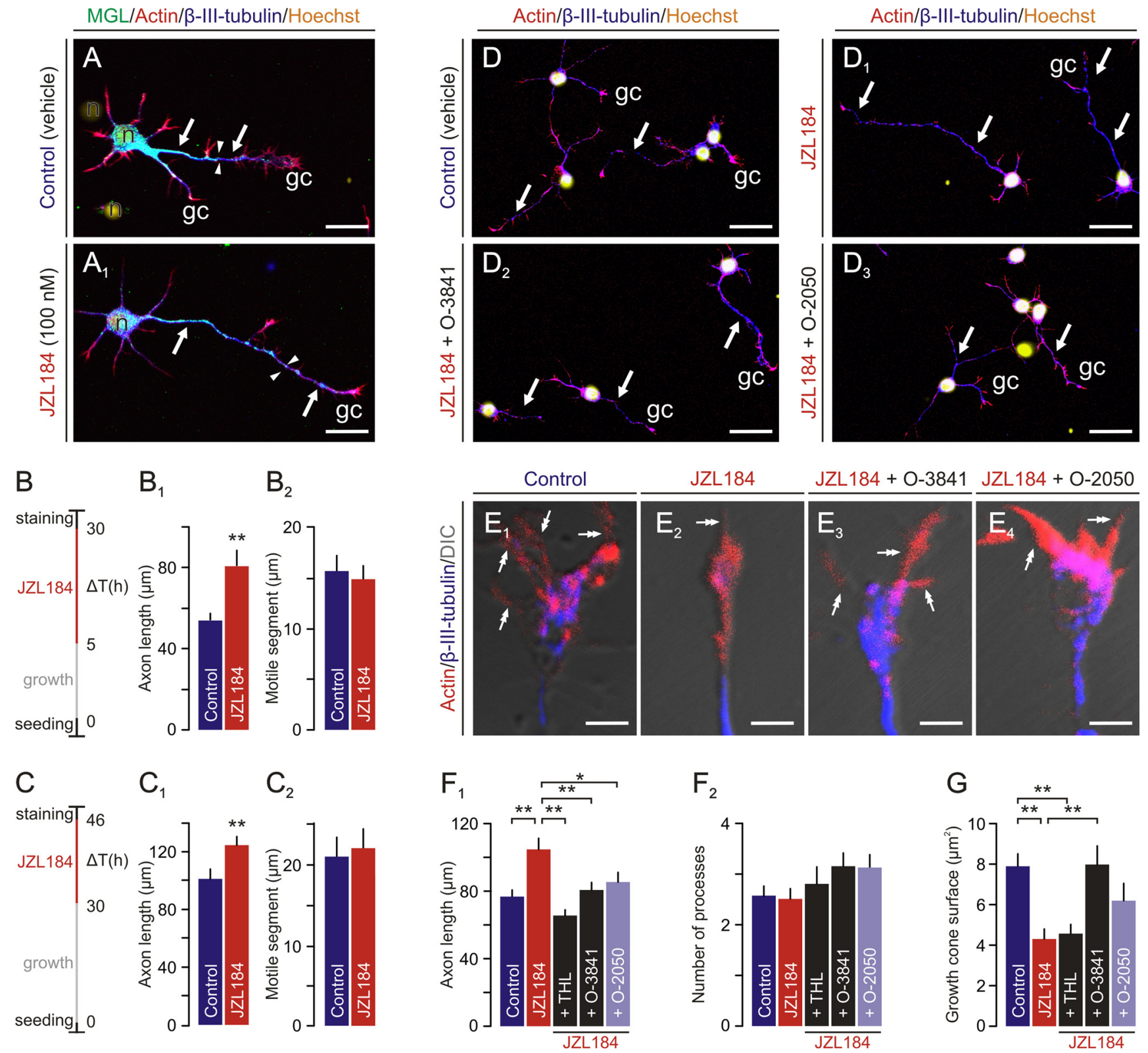

Figure 9. MGL inhibition induces axonal growth. $\boldsymbol{A}_{,} \boldsymbol{A}_{1}$,JZL184 induces elongation of the primary neurite of cortical neurons (arrows) relative to controls. The initial point of axonal MGL gradients decrementing toward the actin ${ }^{+}$growth cones is indicated by arrowheads. $\boldsymbol{B}-\boldsymbol{C}_{2}$, JZL184-induced axonal elongation is unrelated to the time of drug exposure. Cortical neurons were seeded for short $\left(\boldsymbol{B}-\boldsymbol{B}_{2}\right)$ or prolonged $\left(\boldsymbol{C}-\boldsymbol{C}_{2}\right)$ periods and subsequently exposed to JZL184. MGL inhibition invariably evokes an axonal growth response $\left(\boldsymbol{B}_{1}, \boldsymbol{C}_{\mathbf{1}}\right)$. JZL184 does not affect either the length of the motile actin $^{+}$neurite tip $\left(\boldsymbol{B}_{2}, \boldsymbol{C}_{\mathbf{2}}\right)$. D- $\boldsymbol{D}_{\mathbf{3}}$, DAGL inhibition by 0 -3841 as well as $\left(B_{1}\right.$ R blockade by 0 -2050 abolishes JZL 184-induced neurite outgrowth $\left(\boldsymbol{F}_{\mathbf{1}}\right)$ without affecting the number of neurites $\left(\boldsymbol{F}_{\mathbf{2}}\right)$. $\boldsymbol{E}_{\mathbf{1}}-\boldsymbol{E}_{\mathbf{4}}$, Both 0-3841 and 0-2050 markedly alleviate JZL184-induced growth cone collapse $(\boldsymbol{G})$. Note that THL and 0-3841 exert differential effects on growth cone size. ${ }^{*} p<0.05,{ }^{* *} p<0.01$ (Student's $t$ test); $n=25-40$ cells per group. Scale bars: $\boldsymbol{A}_{1}, \boldsymbol{D}_{2}, \boldsymbol{D}_{3}, 20 \mu \mathrm{m} ; \boldsymbol{E}_{\mathbf{1}}-\boldsymbol{E}_{4}, 3 \mu \mathrm{m}$.

ditional level of signaling complexity when alternative eCBs are present, with eCBs conferring specific modalities to neuronal subclass diversification during nervous system induction.

\section{Positional ligand inactivation confers spatial specificity in 2-AG signaling}

Our quantitative morphometry demonstrates that MGL can coexist with both $\mathrm{CB}_{1}$ Rs and DAGL to promote cell-autonomous axonal growth of neocortical pyramidal cells. In contrast, $\mathrm{CB}_{1} \mathrm{Rs}$ are absent from $\mathrm{MGL}^{+}$TCAs. We attribute the scarce coexistence of $\mathrm{MGL}^{+} / \mathrm{CB}_{1} \mathrm{R}^{+}$axonal profiles in thalamic territories to CTAs invading particular nuclei. The remarkable neurochemical dichotomy of CFAs and TCAs in the context of 2-AG signaling led us to propose novel roles for 2-AG signaling during the "handshake" of these axons. The handshake hypothesis implies that axons from the thalamus and from early-born cortical preplate cells meet and intermingle in the basal telencephalon, after which thalamic axons use the scaffold of CFAs to enter the cortical plate (Molnár and Blakemore, 1995). Our findings provide an additional facet of information to this hypothesis by identifying MGL-mediated 2-AG inactivation in TCAs as a mechanism to limit unwanted 2-AG spillover likely masking steep local ligand microgradients, to refine the extracellular 2-AG microgradient map, and to determine $\mathrm{CB}_{1} \mathrm{R}$-dependent directional CFA growth (Fig. $4 E$ ). The ability of 2-AG to act as an extracellular guidance signal is suggested by impaired retrograde signaling in $D A G L^{-/-}$ 
mice (Gao et al., 2010; Tanimura et al., 2010), demonstrating that 2-AG can be liberated from specific neuronal compartments to engage presynaptic $\mathrm{CB}_{1}$ Rs after commuting in the extracellular matrix.

\section{Reconciling eCB-induced chemorepulsion and axonal growth} Because $C_{1} R$ activation powerfully induces cytoskeletal rearrangements (Ishii and Chun, 2002), focal 2-AG catabolism is critical to isolate cellular microdomains in which 2-AG-induced activation of $C_{1}$ Rs will evoke a specific growth response. $C B_{1} R$ activation in axonal growth cones of cortical neurons has been shown previously to induce chemorepulsive steering decisions when presenting an extracellular ligand microgradient (Berghuis et al., 2007). Because both attractive and repulsive extracellular guidance cues must elicit cytoskeletal remobilization of the distal (motile) axon segment to facilitate axonal elongation (either toward or away from the source of the guidance molecule), $\mathrm{CB}_{1} \mathrm{R}$ dependent repulsive growth cone turning ultimately relies on the directional extension of the motile axon segment (Berghuis et al., 2007), with RhoA GTPases triggering cytoskeletal remodeling in the navigating growth cone.

Exposing neurons to homogenously distributed ligands, such as the bath-applied enzyme inhibitors or $\mathrm{CB}_{1} \mathrm{R}$ agonists used here, will evoke neurite outgrowth. However, bath application will eliminate the ability of the chemotropic ligand to evoke directional growth responses. Instead, axonal trajectories will be chaotic in the absence of discrete synthesis and release sites. Therefore, the experimental paradigm we used will only allow us to study whether 2-AG can promote axonal growth per se. Because MGL inhibition by JZL184 couples to an axonal growth response, we conclude that $2-A G$ clearly possesses such a capacity when engaging $C_{1}$ Rs in growth cones. It is noteworthy that JZL184-treated neurons exhibit axonal growth cone morphologies reminiscent of those seen after gradient $\mathrm{CB}_{1} \mathrm{R}$ activation (Berghuis et al., 2007): a clear reduction in the number of filopodia as well as in the surface size of growth cones argues that massive growth cone remodeling occurs when 2-AG levels become elevated. Our finding that O-3841 but not THL reinstates the size and filopodial complexity of axonal growth cones hints that these antagonists may differentially affect DAGL $\alpha$ or DAGL $\beta$ and can have different efficacies to block 2-AG synthesis or off-target effects [e.g., THL can inhibit ABHD12 (Hoover et al., 2008)] in developing neurons.

Overall, our data strongly suggest that 2-AG signaling exerts dual roles in developing neurons by impacting both growth cone navigation and axonal elongation. In this regard, the refined proteasomal regulation of MGL might not only contribute to the maintenance of axonal 2-AG microgradients but can also rapidly reconfigure MGL distribution to occlude protrusive 2-AG signaling. Such a mechanism can be particularly powerful to act as a halting signal to prevent aberrant elongation of an axon beyond its physiologically appropriate postsynaptic target. Notably, MGL stabilization ("overexpression") and inhibition inversely modulate 2-AG availability, which translates into a differential axon growth response regardless of the stage of axon development. The magnitude of axonal growth we observed cannot be augmented by prolonged MGL inhibition, suggesting $\mathrm{CB}_{1} \mathrm{R}$ desensitization or accelerated receptor recycling and removal (Hsieh et al., 1999) once 2-AG levels reach a critical supraphysiological threshold.

MGL is generally viewed to degrade $2-A G$ in the brain. However, Nomura et al. (2010) have reported recently that
MGL can degrade a broad variety of bioactive monoacylglycerols. Therefore, we suggest that the developmentally defined composition of the substrate pool of MGL will determine its metabolic significance. Our experiments cumulatively suggest that the primary target of MGL to modulate axonal growth and guidance is an endogenous $\mathrm{CB}_{1} \mathrm{R}$ agonist synthesized by DAGLs. Although we cannot entirely exclude the contribution of alternative monoacylglycerols to developmental processes, the above molecular characteristics together with an in vivo inverse relationship between neonatal MGL expression and tissue 2-AG concentrations suggest that 2-AG can be a physiologically relevant candidate to mediate axonal growth responses. Assuming that subcellular accumulation of DAGLs and MGL directly reflect their increased focal enzymatic activity, we conclude that the developmental role of MGL is to sculpt the spatial dynamics of 2-AG-rich hotspots, allowing 2-AG to function as a local protrusive signal facilitating neurite elongation. Thus, the spatiotemporal control of 2-AG metabolism is a key determinant of eCB signaling during establishment of the wiring diagram in cortical neuronal networks, and modifications to the subcellular control of $\mathrm{eCB}$ actions may be intrinsic to the pathogenesis of congenital disorders associated with aberrant telencephalic axon patterning.

\section{References}

Aguado T, Monory K, Palazuelos J, Stella N, Cravatt B, Lutz B, Marsicano G, Kokaia Z, Guzmán M, Galve-Roperh I (2005) The endocannabinoid system drives neural progenitor proliferation. FASEB J 19:1704-1706.

Aguado T, Palazuelos J, Monory K, Stella N, Cravatt B, Lutz B, Marsicano G, Kokaia Z, Guzmán M, Galve-Roperh I (2006) The endocannabinoid system promotes astroglial differentiation by acting on neural progenitor cells. J Neurosci 26:1551-1561.

Begbie J, Doherty P, Graham A (2004) Cannabinoid receptor, CB1, expression follows neuronal differentiation in the early chick embryo. J Anat 205:213-218.

Berghuis P, Dobszay MB, Wang X, Spano S, Ledda F, Sousa KM, Schulte G, Ernfors P, Mackie K, Paratcha G, Hurd YL, Harkany T (2005) Endocannabinoids regulate interneuron migration and morphogenesis by transactivating the TrkB receptor. Proc Natl Acad Sci U S A 102:19115-19120.

Berghuis P, Rajnicek AM, Morozov YM, Ross RA, Mulder J, Urbán GM, Monory K, Marsicano G, Matteoli M, Canty A, Irving AJ, Katona I, Yanagawa Y, Rakic P, Lutz B, Mackie K, Harkany T (2007) Hardwiring the brain: endocannabinoids shape neuronal connectivity. Science 316:1212-1216.

Berrendero F, Sepe N, Ramos JA, Di Marzo V, Fernández-Ruiz JJ (1999) Analysis of cannabinoid receptor binding and mRNA expression and endogenous cannabinoid contents in the developing rat brain during late gestation and early postnatal period. Synapse 33:181-191.

Bisogno T, Howell F, Williams G, Minassi A, Cascio MG, Ligresti A, Matias I, Schiano-Moriello A, Paul P, Williams EJ, Gangadharan U, Hobbs C, Di Marzo V, Doherty P (2003) Cloning of the first sn1-DAG lipases points to the spatial and temporal regulation of endocannabinoid signaling in the brain. J Cell Biol 163:463-468.

Bisogno T, Cascio MG, Saha B, Mahadevan A, Urbani P, Minassi A, Appendino G, Saturnino C, Martin B, Razdan R, Di Marzo V (2006) Development of the first potent and specific inhibitors of endocannabinoid biosynthesis. Biochim Biophys Acta 1761:205-212.

Blankman JL, Simon GM, Cravatt BF (2007) A comprehensive profile of brain enzymes that hydrolyze the endocannabinoid 2-arachidonoylglycerol. Chem Biol 14:1347-1356.

Bromberg KD, Ma'ayan A, Neves SR, Iyengar R (2008) Design logic of a cannabinoid receptor signaling network that triggers neurite outgrowth. Science 320:903-909.

Campbell DS, Holt CE (2001) Chemotropic responses of retinal growth cones mediated by rapid local protein synthesis and degradation. Neuron 32:1013-1026.

Chevaleyre V, Takahashi KA, Castillo PE (2006) Endocannabinoid- 
mediated synaptic plasticity in the CNS. Annu Rev Neurosci 29: 37-76.

Coutts AA, Anavi-Goffer S, Ross RA, MacEwan DJ, Mackie K, Pertwee RG, Irving AJ (2001) Agonist-induced internalization and trafficking of cannabinoid $\mathrm{CB}_{1}$ receptors in hippocampal neurons. J Neurosci 21:2425-2433.

Derkinderen P, Valjent E, Toutant M, Corvol JC, Enslen H, Ledent C, Trzaskos J, Caboche J, Girault JA (2003) Regulation of extracellular signal-regulated kinase by cannabinoids in hippocampus. J Neurosci 23:2371-2382.

Dinh TP, Carpenter D, Leslie FM, Freund TF, Katona I, Sensi SL, Kathuria S, Piomelli D (2002) Brain monoglyceride lipase participating in endocannabinoid inactivation. Proc Natl Acad Sci U S A 99:1081910824.

Dotti CG, Sullivan CA, Banker GA (1988) The establishment of polarity by hippocampal neurons in culture. J Neurosci 8:1454-1468.

Fishell G, Hanashima C (2008) Pyramidal neurons grow up and change their mind. Neuron 57:333-338.

Gao Y, Vasilyev DV, Goncalves MB, Howell FV, Hobbs C, Reisenberg M, Shen R, Zhang MY, Strassle BW, Lu P, Mark L, Piesla MJ, Deng K, Kouranova EV, Ring RH, Whiteside GT, Bates B, Walsh FS, Williams G, Pangalos MN, Samad TA, Doherty P (2010) Loss of retrograde endocannabinoid signaling and reduced adult neurogenesis in diacylglycerol lipase knock-out mice. J Neurosci 30:2017-2024.

Giuffrida A, Rodríguez de Fonseca F, Piomelli D (2000) Quantification of bioactive acylethanolamides in rat plasma by electrospray mass spectrometry. Anal Biochem 280:87-93.

Goncalves MB, Suetterlin P, Yip P, Molina-Holgado F, Walker DJ, Oudin MJ, Zentar MP, Pollard S, Yáñez-Muñoz RJ, Williams G, Walsh FS, Pangalos MN, Doherty P (2008) A diacylglycerol lipase-CB2 cannabinoid pathway regulates adult subventricular zone neurogenesis in an age-dependent manner. Mol Cell Neurosci 38:526-536.

Gulyas AI, Cravatt BF, Bracey MH, Dinh TP, Piomelli D, Boscia F, Freund TF (2004) Segregation of two endocannabinoid-hydrolyzing enzymes into pre- and postsynaptic compartments in the rat hippocampus, cerebellum and amygdala. Eur J Neurosci 20:441-458.

Haas KF, Broadie K (2008) Roles of ubiquitination at the synapse. Biochim Biophys Acta 1779:495-506.

Hashimotodani Y, Ohno-Shosaku T, Kano M (2007) Presynaptic monoacylglycerol lipase activity determines basal endocannabinoid tone and terminates retrograde endocannabinoid signaling in the hippocampus. J Neurosci 27:1211-1219.

Hoover HS, Blankman JL, Niessen S, Cravatt BF (2008) Selectivity of inhibitors of endocannabinoid biosynthesis evaluated by activity-based protein profiling. Bioorg Med Chem Lett 18:5838-5841.

Hsieh C, Brown S, Derleth C, Mackie K (1999) Internalization and recycling of the $\mathrm{CB}_{1}$ cannabinoid receptor. J Neurochem 73:493-501.

Ibáñez CF, Ernfors P (2007) Hierarchical control of sensory neuron development by neurotrophic factors. Neuron 54:673-675.

Ishii I, Chun J (2002) Anandamide-induced neuroblastoma cell rounding via the CB1 cannabinoid receptors. Neuroreport 13:593-596.

Kano M, Ohno-Shosaku T, Hashimotodani Y, Uchigashima M, Watanabe M (2009) Endocannabinoid-mediated control of synaptic transmission. Physiol Rev 89:309-380.

Katona I, Urbán GM, Wallace M, Ledent C, Jung KM, Piomelli D, Mackie K, Freund TF (2006) Molecular composition of the endocannabinoid system at glutamatergic synapses. J Neurosci 26:5628-5637.

King AR, Duranti A, Tontini A, Rivara S, Rosengarth A, Clapper JR, Astarita G, Geaga JA, Luecke H, Mor M, Tarzia G, Piomelli D (2007) URB602 inhibits monoacylglycerol lipase and selectively blocks 2-arachidonoylglycerol degradation in intact brain slices. Chem Biol 14:1357-1365.

Ledent C, Valverde O, Cossu G, Petitet F, Aubert JF, Beslot F, Böhme GA, Imperato A, Pedrazzini T, Roques BP, Vassart G, Fratta W, Parmentier M (1999) Unresponsiveness to cannabinoids and reduced addictive effects of opiates in CB1 receptor knockout mice. Science 283:401-404.

Leterrier C, Lainé J, Darmon M, Boudin H, Rossier J, Lenkei Z (2006) Constitutive activation drives compartment-selective endocytosis and axonal targeting of type 1 cannabinoid receptors. J Neurosci 26:3141-3153.

Long JZ, Li W, Booker L, Burston JJ, Kinsey SG, Schlosburg JE, Pavón FJ, Serrano AM, Selley DE, Parsons LH, Lichtman AH, Cravatt BF (2009)
Selective blockade of 2-arachidonoylglycerol hydrolysis produces cannabinoid behavioral effects. Nat Chem Biol 5:37-44.

Maccarrone M, Rossi S, Bari M, De Chiara V, Fezza F, Musella A, Gasperi V, Prosperetti C, Bernardi G, Finazzi-Agrò A, Cravatt BF, Centonze D (2008) Anandamide inhibits metabolism and physiological actions of 2-arachidonoylglycerol in the striatum. Nat Neurosci 11:152-159.

Maison P, Walker DJ, Walsh FS, Williams G, Doherty P (2009) BDNF regulates neuronal sensitivity to endocannabinoids. Neurosci Lett 467:90-94.

Molnár Z, Blakemore C (1995) How do thalamic axons find their way to the cortex? Trends Neurosci 18:389-397.

Morii H, Shiraishi-Yamaguchi Y, Mori N (2006) SCG10, a microtubule destabilizing factor, stimulates the neurite outgrowth by modulating microtubule dynamics in rat hippocampal primary cultured neurons. J Neurobiol 66:1101-1114.

Morozov YM, Torii M, Rakic P (2009) Origin, early commitment, migratory routes, and destination of cannabinoid type 1 receptor-containing interneurons. Cereb Cortex 19 [Suppl 1]:i78-i89.

Mulder J, Aguado T, Keimpema E, Barabás K, Ballester Rosado CJ, Nguyen L, Monory K, Marsicano G, Di Marzo V, Hurd YL, Guillemot F, Mackie K, Lutz B, Guzmán M, Lu HC, Galve-Roperh I, Harkany T (2008) Endocannabinoid signaling controls pyramidal cell specification and longrange axon patterning. Proc Natl Acad Sci U S A 105:8760-8765.

Mulder J, Zilberter M, Spence L, Tortoriello G, Uhlén M, Yanagawa Y, Aujard F, Hökfelt T, Harkany T (2009) Secretagogin is a $\mathrm{Ca}^{2+}$-binding protein specifying subpopulations of telencephalic neurons. Proc Natl Acad Sci U S A 106:22492-22497.

Niehaus JL, Liu Y, Wallis KT, Egertová M, Bhartur SG, Mukhopadhyay S, Shi S, He H, Selley DE, Howlett AC, Elphick MR, Lewis DL (2007) CB1 cannabinoid receptor activity is modulated by the cannabinoid receptor interacting protein CRIP 1a. Mol Pharmacol 72:1557-1566.

Nomura DK, Long JZ, Niessen S, Hoover HS, Ng SW, Cravatt BF (2010) Monoacylglycerol lipase regulates a fatty acid network that promotes cancer pathogenesis. Cell 140:49-61.

Omura S, Matsuzaki K, Fujimoto T, Kosuge K, Furuya T, Fujita S, Nakagawa A (1991) Structure of lactacystin, a new microbial metabolite which induces differentiation of neuroblastoma cells. J Antibiot (Tokyo) 44:117-118.

Straiker A, Hu SS, Long JZ, Arnold A, Wager-Miller J, Cravatt BF, Mackie K (2009) Monoacyl glycerol lipase (MGL) limits the duration of endocannabinoid-mediated depolarization-induced suppression of excitation (DSE) in autaptic hippocampal neurons. Mol Pharmacol 76:1220-1227.

Sugitani Y, Nakai S, Minowa O, Nishi M, Jishage K, Kawano H, Mori K, Ogawa M, Noda T (2002) Brn-1 and Brn-2 share crucial roles in the production and positioning of mouse neocortical neurons. Genes Dev $16: 1760-1765$.

Tamamaki N, Yanagawa Y, Tomioka R, Miyazaki J, Obata K, Kaneko T (2003) Green fluorescent protein expression and colocalization with calretinin, parvalbumin, and somatostatin in the GAD67-GFP knock-in mouse. J Comp Neurol 467:60-79.

Tanimura A, Yamazaki M, Hashimotodani Y, Uchigashima M, Kawata S, Abe M, Kita Y, Hashimoto K, Shimizu T, Watanabe M, Sakimura K, Kano M (2010) The endocannabinoid 2-arachidonoylglycerol produced by diacylglycerol lipase alpha mediates retrograde suppression of synaptic transmission. Neuron 65:320-327.

Torii M, Hashimoto-Torii K, Levitt P, Rakic P (2009) Integration of neuronal clones in the radial cortical columns by EphA and ephrin-A signalling. Nature 461:524-528.

Tucker KL, Meyer M, Barde YA (2001) Neurotrophins are required for nerve growth during development. Nat Neurosci 4:29-37.

Twitchell W, Brown S, Mackie K (1997) Cannabinoids inhibit N- and P/Qtype calcium channels in cultured rat hippocampal neurons. J Neurophysiol 78:43-50.

Uchigashima M, Narushima M, Fukaya M, Katona I, Kano M, Watanabe M (2007) Subcellular arrangement of molecules for 2-arachidonoylglycerol-mediated retrograde signaling and its physiological contribution to synaptic modulation in the striatum. J Neurosci 27:36633676.

Vitalis T, Lainé J, Simon A, Roland A, Leterrier C, Lenkei Z (2008) The type 1 cannabinoid receptor is highly expressed in embryonic cortical projec- 
tion neurons and negatively regulates neurite growth in vitro. Eur J Neurosci 28:1705-1718.

Walker DJ, Suetterlin P, Reisenberg M, Williams G, Doherty P (2010) Down-regulation of diacylglycerol lipase-alpha during neural stem cell differentiation: Identification of elements that regulate transcription. J Neurosci Res 88:735-745.

Watson S, Chambers D, Hobbs C, Doherty P, Graham A (2008) The endocannabinoid receptor, $\mathrm{CB} 1$, is required for normal axonal growth and fasciculation. Mol Cell Neurosci 38:89-97.

Williams EJ, Walsh FS, Doherty P (2003) The FGF receptor uses the endocannabinoid signaling system to couple to an axonal growth response. J Cell Biol 160:481-486.
Xiang Y, Li Y, Zhang Z, Cui K, Wang S, Yuan XB, Wu CP, Poo MM, Duan S (2002) Nerve growth cone guidance mediated by G protein-coupled receptors. Nat Neurosci 5:843-848.

Yoshida T, Fukaya M, Uchigashima M, Miura E, Kamiya H, Kano M, Watanabe M (2006) Localization of diacylglycerol lipase- $\alpha$ around postsynaptic spine suggests close proximity between production site of an endocannabinoid, 2-arachidonoyl-glycerol, and presynaptic cannabinoid $\mathrm{CB}_{1}$ receptor. J Neurosci 26:4740-4751.

Zorina Y, Iyengar R, Bromberg KD (2010) Cannabinoid 1 receptor and interleukin-6 receptor together induce integration of protein kinase and transcription factor signaling to trigger neurite outgrowth. J Biol Chem 285:1358-1370. 